\title{
Future Transient Testing of Advanced Fuels
}

Summary of the May 4-5, 2009 Transient Testing Workshop Held at Idaho National Laboratory

September 2009

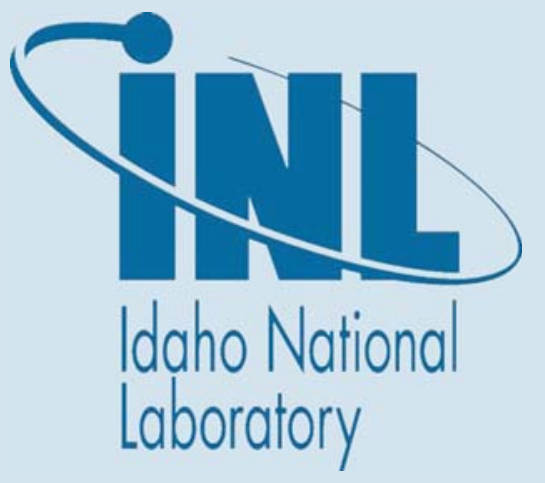

The INL is a U.S. Department of Energy National Laboratory operated by Battelle Energy Alliance 


\section{DISCLAIMER}

This information was prepared as an account of work sponsored by an agency of the U.S. Government. Neither the U.S. Government nor any agency thereof, nor any of their employees, makes any warranty, expressed or implied, or assumes any legal liability or responsibility for the accuracy, completeness, or usefulness, of any information, apparatus, product, or process disclosed, or represents that its use would not infringe privately owned rights. References herein to any specific commercial product, process, or service by trade name, trade mark, manufacturer, or otherwise, does not necessarily constitute or imply its endorsement, recommendation, or favoring by the U.S. Government or any agency thereof. The views and opinions of authors expressed herein do not necessarily state or reflect those of the U.S. Government or any agency thereof. 


\section{Future Transient Testing of Advanced Fuels}

September 2009

Idaho National Laboratory Idaho Falls, Idaho 83415

http://www.inl.gov

Prepared for the

U.S. Department of Energy

Office of Nuclear Energy

Under DOE Idaho Operations Office

Contract DE-AC07-05ID14517 



\section{Future Transient Testing of Advanced Fuels}

INL/EXT-09-16392

Revision 0

September 2009 



\section{EXECUTIVE SUMMARY}

The transient in-reactor fuels testing workshop was held on May 4-5, 2009 at Idaho National Laboratory. The purpose of this meeting was to provide a forum where technical experts in transient testing of nuclear fuels could meet directly with technical instrumentation experts and nuclear fuel modeling and simulation experts to discuss needed advancements in transient testing to support a basic understanding of nuclear fuel behavior under off-normal conditions. The workshop was attended by representatives from Commissariat à l'Énergie Atomique CEA, Japanese Atomic Energy Agency (JAEA), Department of Energy (DOE), AREVA, General Electric - Global Nuclear Fuels (GE-GNF), Westinghouse, Electric Power Research Institute (EPRI), universities, and several DOE national laboratories.

The meeting began with a description of the TREAT Transient Reactor Test Facility - an overview of the transient testing was conducted in the facility from 1959 through 1994 in support of U.S. thermal and fast reactor development programs and related TREAT-experiment support capabilities. This was complemented by presentations on transient fuels testing by Japan and France: JAEA's current transient testing using its Nuclear Safety Research Reactor (NSRR) facility at O-Arai and the Impulse Graphite Reactor (IGR) facility in Kazakhstan, and CEA's capability for transient testing of nuclear fuels in flowing water loops in its transient test facility, CABRI, in Cadarache, France.

The workshop then turned to the testing needs for future advanced reactor systems. In the development of advanced fuels for future advanced reactor systems, it has historically taken 1 to 2 decades to generate the information and understanding needed to assure reliable reactor performance. Developing a base understanding of nuclear fuel performance is an important key to shortening this development cycle and is generally believed to be best accomplished through detailed multi-scale modeling and simulation capabilities coupled with experiments that directly support modeling and simulation. Since the new fuel designs for advanced reactors in many cases utilize fuel materials, which have not previously been tested under transient conditions, there is a special need for transient testing of these materials to generate the benchmark data for the modeling and simulation research and development process.

Transient testing of nuclear fuels has typically been conducted at various stages of the fuel development cycle, depending upon the particular issues that may need experiments to help resolve. Fundamental fuel transient behavior characteristics, if determined early, can help guide fuel design considerations. Integral testing can then be conducted later to demonstrate more-complex behavior characteristics of more-mature fuel designs, including beyond design basis behaviors. These data are important to provide technical justification to a licensing authority that the transient behavior of the newly designed nuclear fuel system is sufficiently understood and predicted by integral, accident analysis codes. 
Advanced modeling and simulation capabilities that describe the base behavior of advanced fuels may significantly reduce the need for transient fuel testing, but such analytical capabilities will need empirical data for guidance and validation. Obtaining the types of data needed for such multi-scale modeling will require new experiment methods and instrumentation to allow finer time and spatial resolution.

Transient testing of fuels and materials generates information required for advanced fuels in future nuclear power plants. Future nuclear power plants will rely heavily on advanced computer modeling and simulation that describes fuel behavior under off-normal conditions. TREAT is an ideal facility for this testing because of its flexibility, proven operation and material condition. The opportunity exists to develop advanced instrumentation and data collection that can support modeling and simulation needs much better than was possible in the past. In order to take advantage of these opportunities, test programs must be carefully designed to yield basic information to support modeling before conducting integral performance tests.

An early start of TREAT and operation at low power would provide significant dividends in training, development of instrumentation, and checkout of reactor systems. Early start of TREAT (2015) is needed to support the requirements of potential users of TREAT and include the testing of full length fuel irradiated in the FFTF reactor. The capabilities provided by TREAT are needed for the development of nuclear power and the following benefits will be realized by the refurbishment and restart of TREAT.

- TREAT is an absolute necessity in the suite of reactor fuel test capabilities

- TREAT yields valuable information on reactivity effects, margins to failure, fuel dispersal, and failure propagation

- Most importantly, interpretation of TREAT experiment results is a stringent test of the integrated understanding of fuel performance. 


\section{CONTENTS}

EXECUTIVE SUMMARY

ACRONYMS ix

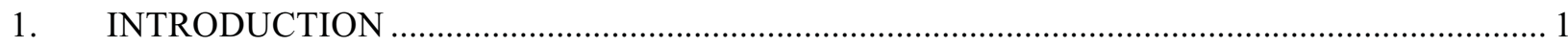

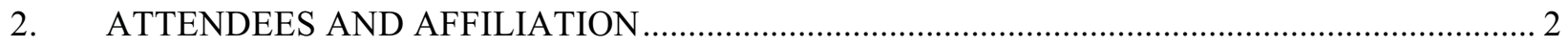

3. HISTORY OF TRANSIENT TESTING IN TREAT (ART WRIGHT) ........................................ 4

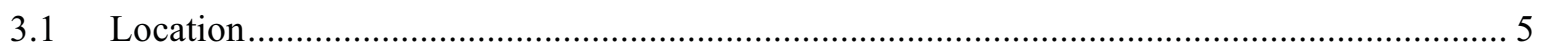

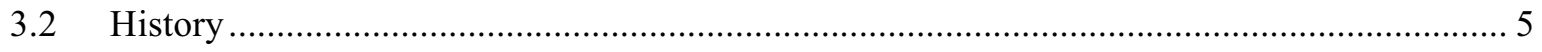

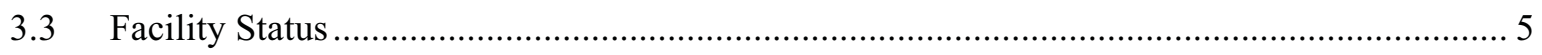

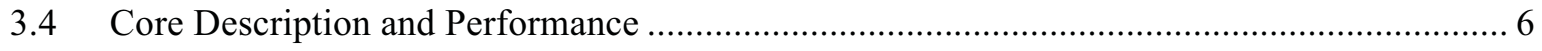

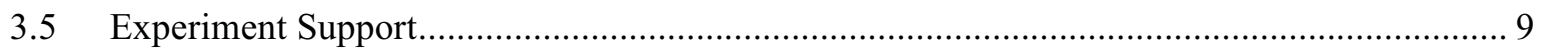

3.6 TREAT Testing: Specific Goals, Techniques and Useful Results (Ted Bauer) ................... 11

3.7 Transient Testing Support Infrastructure in HFEF (Greg Teske) ...................................... 13

4. CURRENT STATUS OF TRANSIENT TESTING PROGRAMS AT CEA AND JAEA .............. 17

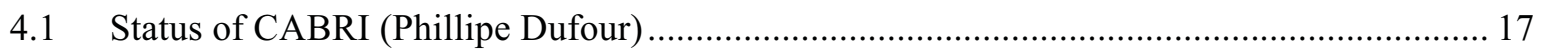

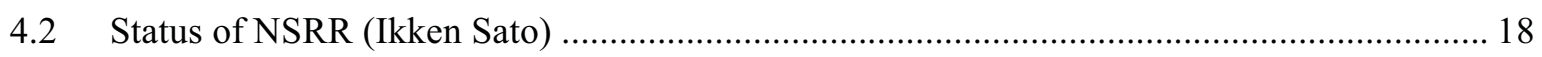

5. A SCIENTIFIC APPROACH TO TRANSIENT TESTING (GEORGE IMEL) ......................... 20

6. DESCRIPTION OF HISTORICAL TREAT INSTRUMENTATION (KEVIN CARNEY)........... 21

7. IMAGING OF DYNAMIC SYSTEMS AND FUTURE INSTRUMENTATION

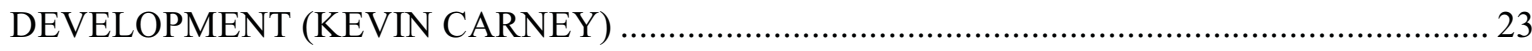

8. EXPERIMENTAL STUDY AND SIMULATION FOR A VERY FAST TRANSIENT EVENT FOR MATERIALS BEHAVIOR (CETIN UNAL) ......................................................... 25

9. MODELING AND SIMULATION DEVELOPMENT NEEDS FOR TRANSIENT

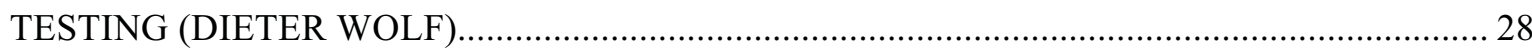

10. SUMMARY OF NEEDS FOR TRANSIENT TESTING IN SUPPORT OF NUCLEAR

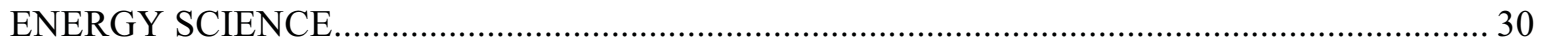

10.1 Input from Light-Water Reactor Industry (Nam Dinh) ................................................... 30

10.2 Input from High-Temperature Gas Reactor (Dave Petti) ................................................... 30

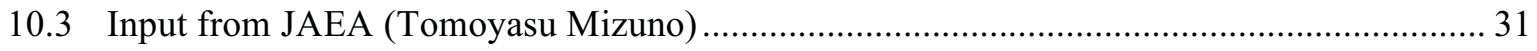

10.4 Input from AFCI Fuel Cycle Research and Development (Steve Hayes)........................... 33

10.4.1 AFCI Transient Testing Requirements ................................................................. 33

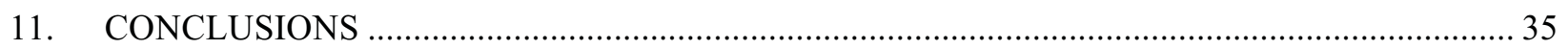

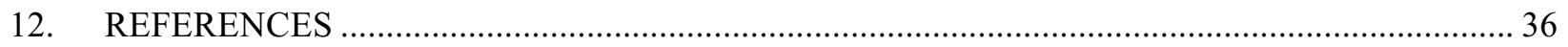




\section{FIGURES}

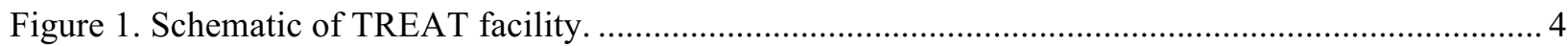

Figure 2. Photograph of the Materials and Fuels Complex showing TREAT in the background

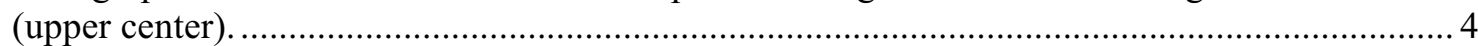

Figure 3. Photograph of TREAT Reactor showing the Hodoscope on the north face of the reactor and a cask atop the radiography stand on the west face. ....................................................... 6

Figure 4. Photograph of experiment loop handling on top of the reactor. ................................................. 8

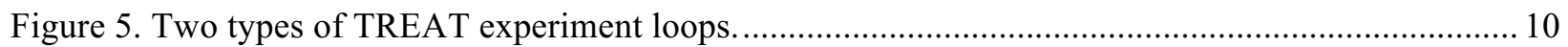

Figure 6. Example results from TREAT power to melt determination....................................................... 12

Figure 7. Example of fuel failure mode determination results................................................................. 12

Figure 8. Stripped sodium loop photographed in the HFEF hot cells................................................... 14

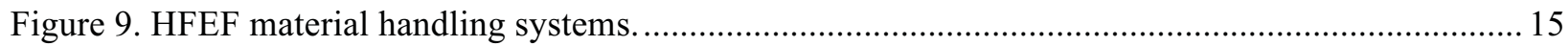

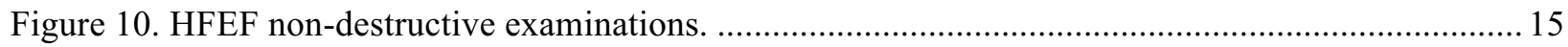

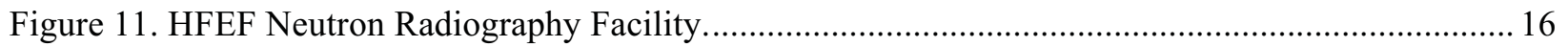

Figure 12. Schematic of the CABRI Facility (Cadarache, France) .......................................................... 17

Figure 13. NSRR transient facility operated by JAEA in Japan............................................................ 18

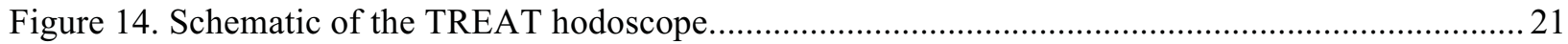

Figure 15. Example of analyzed TREAT hodoscope data (fuel motion with time).................................22

Figure 16. Hierarchical Multi-scale Simulation of Nuclear Fuel..........................................................2 28

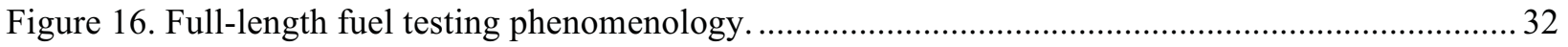

\section{TABLES}

Table 1. Summary of TREAT transient test pulse conditions................................................................ 7

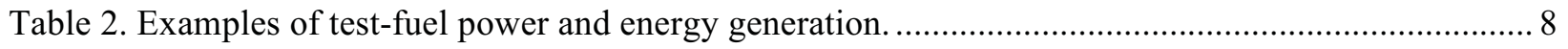

Table 3. Experiment vehicle types designed for TREAT. ................................................................ 9 


\section{ACRONYMS}

ACPR annular core pulse reactor

AFCI Advanced Fuel Cycle Initiative

ATR Advanced Test Reactor

BAPL Bettis Atomic Power Laboratory

BWR Boiling Water Reactor

CABRI Transient test facility operated by CEA

CDE Core Demonstration Experiment

CEA Commissariat à l'Énergie Atomique

DOE Department of Energy

DOE-ID Department of Energy Idaho Operations Office

DSA Documented Safety Assessment

EPRI Electric Power Research Institute

FFTF Fast Flux Test Facility

GACID Global Actinide Cycle International Demonstration

GE-GNF General Electric - Global Nuclear Fuels

HFEF Hot Fuel Examination Facility

IGR Impulse Graphite Reactor

INL Idaho National Laboratory

JAEA Japanese Atomic Energy Agency

JMTR Japanese Material Test Reactor

LANL Los Alamos National Laboratory

LECA Nuclear Fuel Examination Facility in Cadarache, France

LMFBR Liquid Metal Fast Breeder Reactor

LWR light-water reactor

M\&S modeling and simulation

MFC Materials and Fuels Complex

MOX mixed oxide

NRAD Neutron Radiography Reactor

NSRR Nuclear Safety Research Reactor

ODS Oxide Dispersion Strengthened

ORT Operational Readiness Testing

PCF power coupling factor

PIE Post-Irradiation Examination 
PNC Power Reactor and Nuclear Fuel Development Corporation (pre-JAEA)

PWR pressurized water reactor

RIA Reactivity Initiated Accident

RSWF Radioactive Storage and Waste Facility

SAR Safety Analysis Report

TED total fission-energy deposition

TREAT Transient Reactor Test Facility

TRIGA Pulse type test and training reactor 


\section{Future Transient Testing of Advanced Fuels}

\section{INTRODUCTION}

There are three objectives to this meeting and summary report. The first objective stems from the new and novel methods that are being used to investigate the behavior of nuclear fuels. High performance computing now allows the use of modeling and simulation techniques that were previously not possible during historical nuclear energy development programs. The increased level of detail in the scientific study of nuclear systems requires expanding the database to verify and validate the new nuclear system performance codes, including data regarding the transient behavior of the nuclear systems. This meeting seeks to define the scientific transient testing needs of the nuclear research community.

Secondly, the push to understand material behavior at atomistic scales leads to the desire for experiment testing instrumentation suitable for investigating behaviors at this scale. The meeting sought to identify the scientific data needs for factoring into future transient testing facilities.

Thirdly, the meeting aimed to establish requirements for interpretation of transient testing data to support high performance modeling and simulation needs. 


\section{ATTENDEES AND AFFILIATION}

\begin{tabular}{|c|c|c|}
\hline First Name & Last Name & Affiliation \\
\hline William & Bass & Department of Energy (DOE) \\
\hline Theodore & Bauer & Argonne National Lab \\
\hline Jeff & Benson & Idaho National Laboratory \\
\hline Kermit & Bunde & DOE \\
\hline James & Cahalan & Argonne National Laboratory \\
\hline Jon & Carmack & Idaho National Laboratory \\
\hline Douglas & Crawford & Global Nuclear Fuel \\
\hline Nam & Dinh & Idaho National Laboratory \\
\hline Philippe & Dufour & CEA \\
\hline Gary & Engelstad & Idaho National Laboratory \\
\hline Phillip & Finck & Idaho National Laboratory \\
\hline Raymond & Furstenau & DOE-Idaho Operations Office (ID) \\
\hline Tony & Hill & Los Alamos National Laboratory \\
\hline George & Imel & Idaho State University \\
\hline Richard & Jacobsen & Idaho State University \\
\hline John & Kennedy & Idaho National Laboratory \\
\hline John & Kotek & Gallatin Public Affairs \\
\hline Francette & Lemoine & CEA \\
\hline Paul & Lisowski & DOE \\
\hline Heather & MacLean & Idaho National Laboratory \\
\hline William & Mangan & Burns and Roe Enterprises, Inc. \\
\hline Jerry & Mariner & Bettis Atomic Power Laboratory (BAPL) \\
\hline Kenneth & McClellan & Los Alamos National Lab \\
\hline Gerry & McCormick & Idaho National Laboratory \\
\hline Matea & McCray & Department of Energy \\
\hline Harold & McFarlane & Idaho National Laboratory \\
\hline Mitch & Meyer & Idaho National Laboratory \\
\hline Dennis & Miotla & DOE \\
\hline David & Mitchell & Westinghouse Electric Company \\
\hline Tomoyasu & Mizuno & Japan Atomic Energy Agency (JAEA) \\
\hline Calvin & Ozaki & Idaho National Laboratory \\
\hline Edward & Parma & Sandia National Laboratory \\
\hline Michael & Patterson & Idaho National Laboratory \\
\hline Ramprashad & Prabhakaran & University of Idaho \\
\hline Ross & Radel & Sandia National Laboratory \\
\hline John & Sackett & Idaho National Laboratory \\
\hline Hiroshi & Sagara & Idaho National Laboratory \\
\hline
\end{tabular}




\begin{tabular}{|l|l|l|}
\hline \multicolumn{1}{|c|}{ First Name } & \multicolumn{1}{c|}{ Last Name } & \multicolumn{1}{c|}{ Affiliation } \\
\hline Ikken & Sato & Japan Atomic Energy Agency \\
\hline Tansel & Selekler & Department of Energy \\
\hline Casey & Stengel & BAPL \\
\hline Mary Catherine & Thelen & Idaho National Laboratory \\
\hline Cetin & Unal & Los Alamos National Laboratory \\
\hline Thomas & Vergona & BAPL \\
\hline Leon & Walters & Leon Walters \\
\hline Arthur & Wright & Argonne National Laboratory \\
\hline Frederick & Yapuncich & AREVA \\
\hline Ken & Yueh & Electric Power Research Institute \\
\hline
\end{tabular}




\section{HISTORY OF TRANSIENT TESTING IN TREAT (ART WRIGHT)}

TREAT (Transient Reactor Test Facility) is an air-cooled, thermal, heterogeneous test facility designed to evaluate reactor fuels and structural materials under conditions that simulate various types of transient overpower and under-cooling situations in a nuclear reactor. Fuel meltdowns metal-water reactions, thermal interaction between overheated fuel and coolant, and the transient behavior of ceramic fuel for high-temperature systems can be studied. In its steady-state mode of operation, TREAT can be used as a large neutron-radiography facility and can examine assemblies up to $15 \mathrm{ft}$ long. A schematic of the TREAT transient test facility is shown in Figure 1 and a photograph of the Materials and Fuels Complex with TREAT in the background is shown in Figure 2.

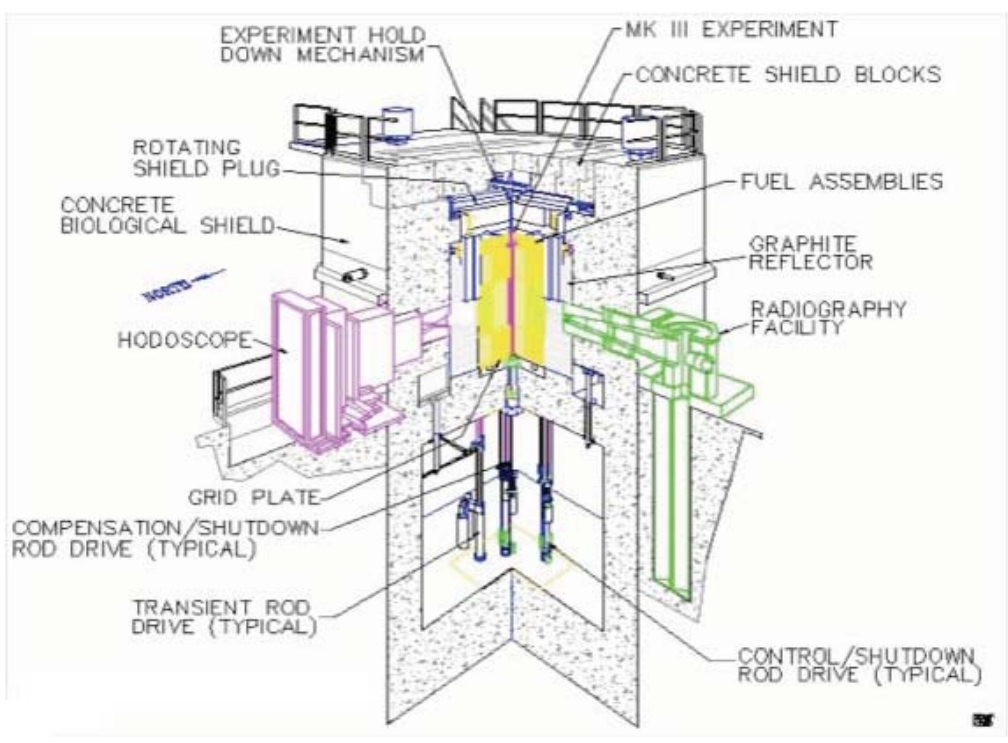

Figure 1. Schematic of TREAT facility.

The contributions by TREAT to the reactor safety program were threefold: (1) to provide basic data for predicting the safety margin of fuel designs and the severity of potential accidents, (2) to serve as a proving ground for fuel concepts design to reduce or preclude the consequent hazards associated with potential accidents, and (3) to provide non-destructive test data through neutron radiography of fuel samples. These same objectives exist today for advanced fuel development and modeling to understand existing fuels better.

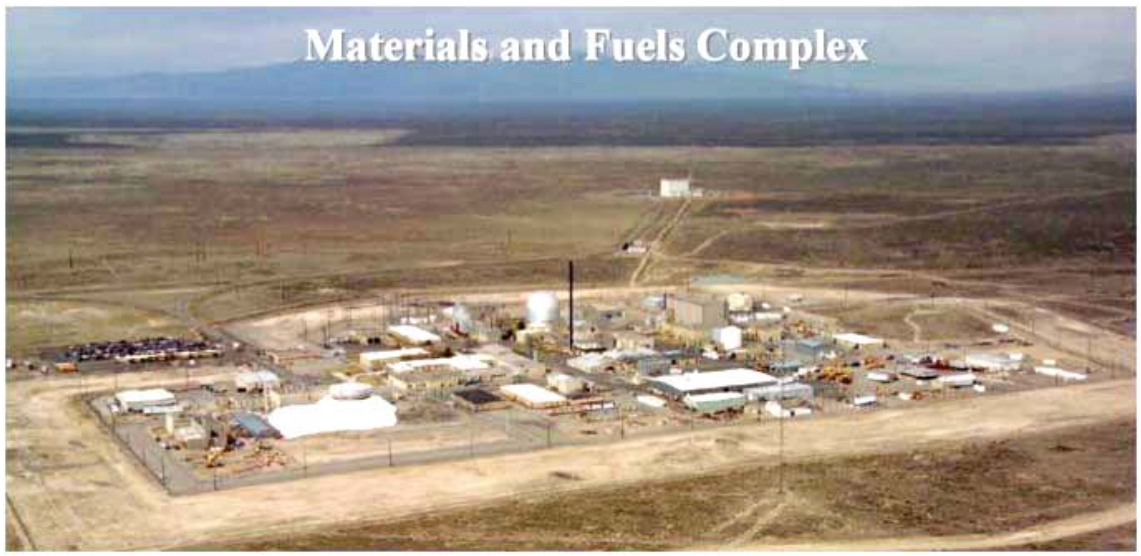

Figure 2. Photograph of the Materials and Fuels Complex showing TREAT in the background (upper center). 


\subsection{Location}

TREAT is located at the Materials and Fuels Complex (MFC) at the Idaho National Laboratory (INL) approximately 11 miles from INL's east boundary and 4 miles north of U.S. Highway 20. The TREAT complex comprises reactor and control buildings located $1300 \mathrm{~m}$ and $530 \mathrm{~m}$, respectively, northwest of the EBR-II containment vessel. Other auxiliary buildings are adjacent to both the reactor and control buildings.

\subsection{History}

Construction of TREAT by the Teller Construction Co., Portland, Oregon, began in February 1958 and was completed in early November 1958. The reactor first achieved criticality on February 23, 1959. Major reactor building additions were made in 1963, 1972, 1979, and 1982. The reactor underwent a major upgrade that included installation of new instrumentation and control systems as well as refurbishment of the rod drive systems in 1988. The reactor was operated from February of 1958 until April of 1994. During that time, 6,604 reactor startups and 2,885 transient irradiations were completed generating a total of 2,600,000 mega-Joules of reactor energy.

\subsection{Facility Status}

The overall condition of the facility is excellent. The facility is radiologically clean and is free of industrial hazards. The instrumentation and control systems are in excellent condition and have been maintained in an operable status. The original TREAT fuel is still in excellent condition and can be expected to remain in service indefinitely. (The life expectancy of the original fuel is determined by oxidation of the zircaloy cladding). The original fuel can safely remain in service until 15 mils of the $25 \mathrm{mil}(0.64 \mathrm{~mm})$ cladding has been lost due to oxidization. The thickness of the zircaloy cladding, which has been lost due to oxidation, is currently estimated to be approximately 1 mil.

Two bridge cranes can access the reactor area to handle large casks and experimental hardware. All of the facility lifting and handling equipment as well as the building utilities are operable and being used to support non-reactor experiments conducted at the facility.

The computer components of the TREAT Hodoscope (fuel motion monitoring system) and experimental data acquisition systems are old, and although functional, no longer have adequate vendor support. Improving the instrumentation and data collection systems is a major opportunity for advancing the value of TREAT for transient testing. 


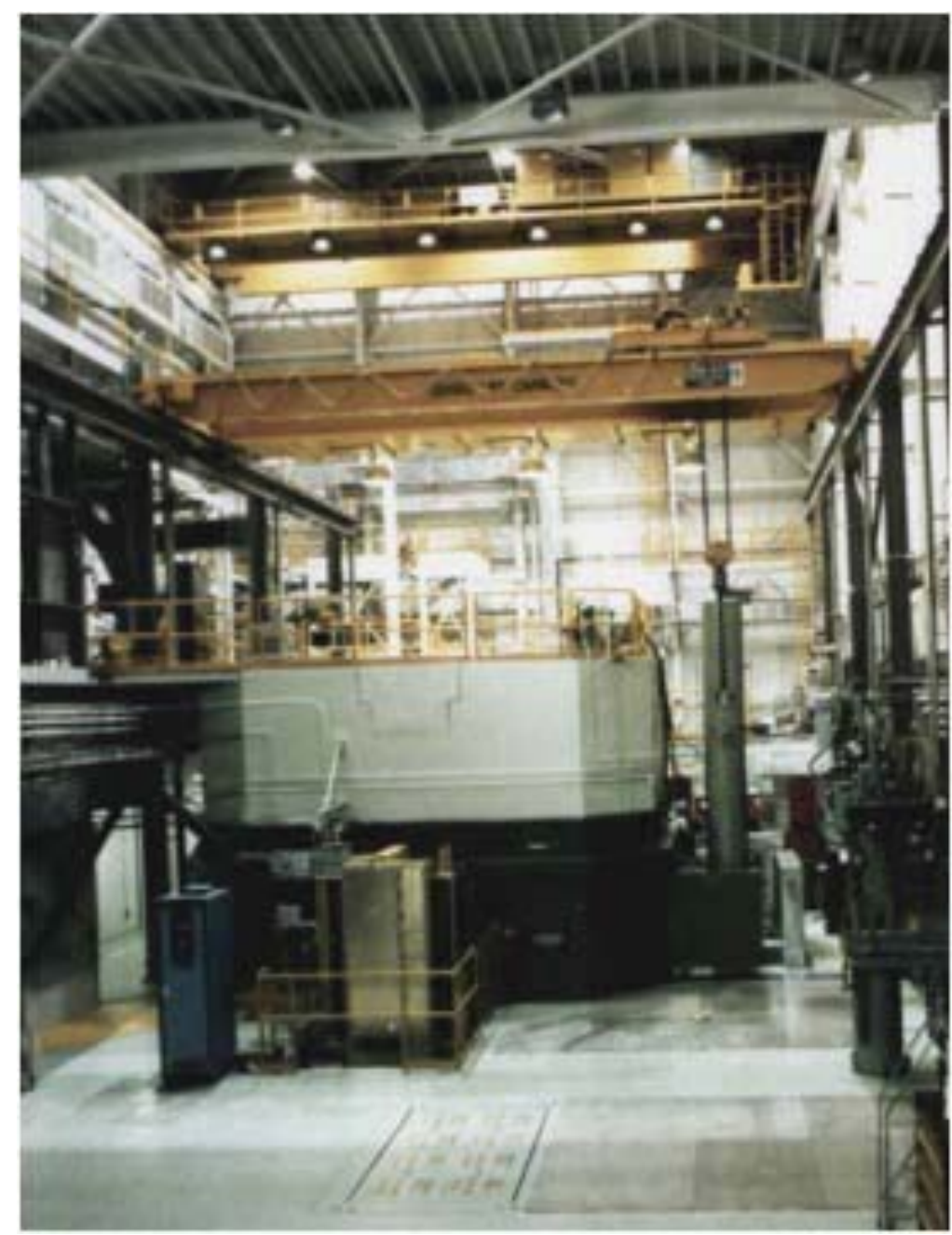

Figure 3. Photograph of TREAT Reactor showing the Hodoscope on the north face of the reactor and a cask atop the radiography stand on the west face.

\subsection{Core Description and Performance}

The TREAT core is located in a concrete biological shield $5 \mathrm{ft}$ thick. The design of the concrete reactor shielding allows personnel access around the reactor during steady-state $(100 \mathrm{~kW})$ operation. The shield contains numerous penetrations that can be used to support experiment and reactor operations. The core is air cooled and designed to remove the heat generated during steady-state operations or following transient operations.

The core consists of a $19 \times 19$ square array of fuel and reflector assemblies. Surrounding the array is a permanent graphite reflector $2 \mathrm{ft}(0.6 \mathrm{~m})$ thick. The TREAT fuel assemblies are $4 \mathrm{in}^{2}$ and $8 \mathrm{ft}$ long. The assemblies are made up of a $4-\mathrm{ft}(122 \mathrm{~cm})$ active fuel section, with two 2-ft axial graphite reflector sections. Experiment vehicles (e.g., loops or capsules) customarily have as many as 21 fuel assemblies.

The TREAT reactor fuel is a diluted mixture of fine particles of highly enriched $\mathrm{UO}_{2}$ in graphite and carbon. The ${ }^{235} \mathrm{U}$ is approximately $0.2 \%$ by weight of the total mixture. This design permits rapid transfer of the fission energy into the graphite and carbon, which results in a rapid and uniform heat up of the moderator. This process results in essentially instantaneously acting, large, negative-temperature coefficients of reactivity, and hence, self-limiting nuclear transients. 
The TREAT core loading is optimized for each experiment to meet the size, reactivity, and diagnostic requirements of the experiment. Figure 4 shows a photograph of an experiment being handled on top of the TREAT reactor. The reactor is capable of developing a range of transient shapes and sizes. The maximum core power and energy capabilities are dependent on administrative limits related to both the core loading and the type of transient being performed. These administrative limits control the peak temperatures of the core fuel elements and are intended to ensure long core life.

Four modes of power operation are possible. Three are transient modes, as noted in Table 1 and described below. The computer systems that control the reactor and monitor the experiment are linked together to provide the capability to make predetermined decisions controlling the reactor and/or experiment system during the course of a transient.

A. "Temperature-limited" transients are single-power bursts generated by a sudden step input of reactivity initiated at a very low power level and terminated by the negative temperature coefficient of reactivity, resulting in a Gaussian, or bell-shaped, power curve. Larger amounts of reactivity input create power-time histories that are narrower, reach higher peak power, and generate more energy. The most energetic burst has a $100 \mathrm{~ms}$ width at half-peak power, a peak power of $18 \mathrm{GW}$, and core energy generation of $2600 \mathrm{MJ}$. A pulse half-width as low as $40 \mathrm{~ms}$ is potentially achievable.

Temperature-limited transients may also be terminated by a reactor shutdown, thus limiting the energy and providing a narrower pulse width.

B. "Shaped transients," which are fully controlled by the TREAT automatic reactor control system. A variety of shapes is possible, depending on experimenter requirements. The control system is capable of controlling the reactor power for power levels up to 10,000 MW and periods between +100 msec and -100 msec. Typically, shaped transients are several seconds to tens of seconds long, with peak power up to 3,000 MW and core energy between 800 and $1900 \mathrm{MJ}$. A power shape commonly used in past transient overpower experiments provided medium-power for a few seconds to preheat the test fuel, followed by a power rise to an experimenter-specified maximum power at a specified rise rate, and then a quick power drop, in some cases to a low level that is maintained for several seconds to simulate decay heating. The fast power rise portion of some shaped transients is temperature limited (caused by a step increase in reactivity).

C. "Extended" power transients, which are also shaped to meet experimenter requirements, involve both computer control of the transient rods and manual control of the slower-acting control rods. This allows additional reactivity to be inserted and additional energy to be generated in the core. During typical extended transients, which last for many minutes, the power level is approximately a few MW, and up to about $2600 \mathrm{MJ}$ is generated by the core.

D. Steady-state operation is limited to $100 \mathrm{~kW}$ core power, which provides the neutron flux needed for neutron radiography.

Table 1. Summary of TREAT transient test pulse conditions.

\begin{tabular}{|l|l|l|l|l|}
\hline \multicolumn{1}{|c|}{ Category Type } & Typical Duration & \multicolumn{1}{|c|}{ Control Mode } & $\begin{array}{c}\text { Maximum Core } \\
\text { Power } \\
\text { (MW) }\end{array}$ & $\begin{array}{c}\text { Maximum Core } \\
\text { Energy } \\
\text { (MJ) }\end{array}$ \\
\hline Shaped & A few seconds & Computer & 10,000 & 2900 \\
\hline $\begin{array}{l}\text { Single Burst } \\
\text { by rod step) }\end{array}$ & $\begin{array}{l}\text { Less than } \\
1 \text { second }\end{array}$ & Rod step & 19,000 & 2900 \\
\hline Extended & Minutes & $\begin{array}{l}\text { Computer and } \\
\text { Manual }\end{array}$ & Several & $\geq 2600$ \\
\hline
\end{tabular}


The ratio between the fission power generated in the test fuel and the power generated in the TREAT core is called the power coupling factor (PCF). It is expressed in units of watts per gram of test fuel per MW of TREAT power (W/g-MW), or equivalently, in units of joules per gram of test fuel per MJ of TREAT energy (J/g-MJ). The total fissionenergy deposition (TED) in the test fuel is thus the product of the PCF times the total core energy generated. The power coupling is highly dependent on the experiment and test fuel design. The power coupling for dilute ${ }^{235} \mathrm{U}$ in a neutronically transparent vessel will be approximately $4.0 \times 10^{12}$ fissions/gram- ${ }^{235} \mathrm{U} /$ MW-TREAT. Some practical examples of power coupling factors and corresponding total test fuel energy generation are indicated in Table 2.

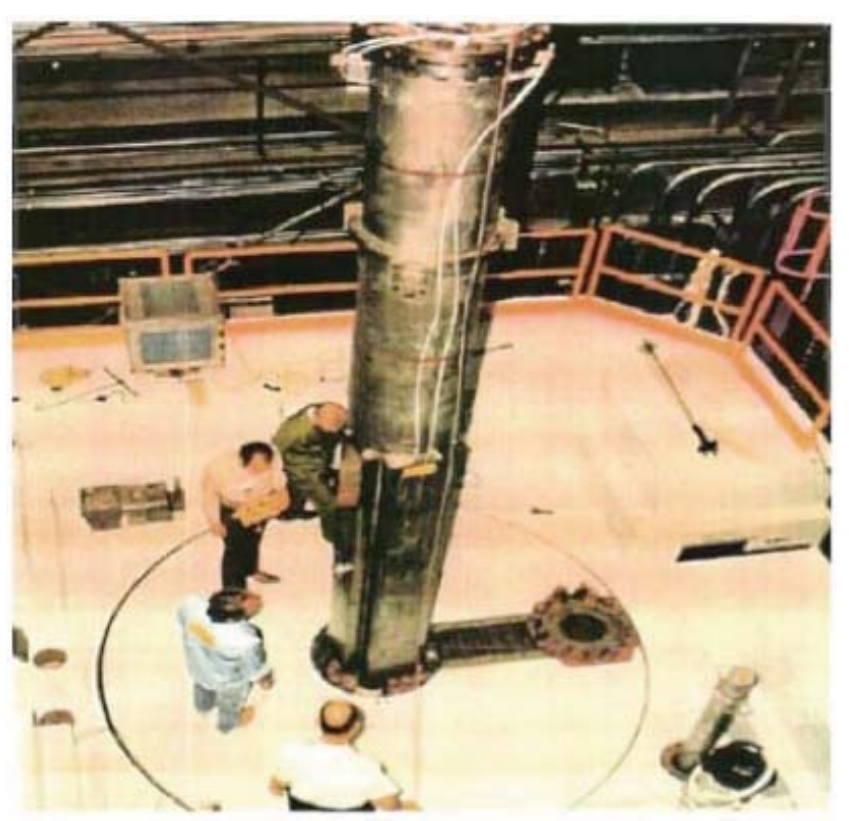

Figure 4. Photograph of experiment loop handling on top of the reactor.

Table 2. Examples of test-fuel power and energy generation.

\begin{tabular}{|l|l|c|c|}
\hline \multicolumn{1}{|c|}{ Fuel Type } & \multicolumn{1}{|c|}{ Power-time History } & PCF, J/g-MJ & TED*, kJ/g \\
\hline $\begin{array}{l}\text { Fast Reactor } \\
60 \mathrm{wt} \% \text { U-235 in Fuel } \\
\text { (no Pu) }\end{array}$ & Shaped transient & 5 & 9 \\
\hline $\begin{array}{l}\text { Fatural burst } \\
30 \mathrm{wt} \% \text { Pu in HM, }\end{array}$ & Shaped transient & 5 & 13 \\
Natural U & & 3 & 4.5 \\
\hline $\begin{array}{l}\text { PWR } \\
5 \% \text { enr., } \\
80 \text { GWd/MTM }\end{array}$ & Natural burst & 0.9 & 1.2 \\
\hline $\begin{array}{l}\text { CANDU } \\
\text { Natural U } \\
\text { Zero Burnup }\end{array}$ & - FWHM 65-70 msec & 0.9 & 0.4 \\
\hline $\begin{array}{l}\text { PWR } \\
8 \% \text { enr., }\end{array}$ & 1 to 2 sec having FWHM of \\
35 GWd/MTM & Extended transient of & Not meaningful & 1.0 \\
\hline
\end{tabular}

$* \mathrm{TED}=$ total fission energy deposition in test fuel 


\subsection{Experiment Support}

A number of experiment types have been designed and used in the TREAT reactor. Table 3 provides a summary of the experiment vehicle types used in the TREAT reactor. The TREAT fast neutron hodoscope can provide test-fuel-motion diagnostics information during experiments. Three multi-channel neutron collimators are available. The one most often used has a viewing region at the core center of $66 \mathrm{~mm}$ (10 pixels) wide $\times 1200 \mathrm{~mm}$ (36 pixels) high and provides spatial resolution as low as $0.2 \mathrm{~mm}$ horizontally and $1.0 \mathrm{~mm}$ vertically. Smaller and larger collimators are also available. The neutron radiography facility alongside the reactor can accommodate most types of experiment vehicles that have been used. Data acquisition capabilities are also available. High-resolution neutron radiography capability exists at the nearby Hot Fuel Examination Facility, where experiment vehicles (loops or capsules) may be assembled and disassembled, and where metallography/ceramography can be performed.

Table 3. Experiment vehicle types designed for TREAT.

\begin{tabular}{cll}
\hline \multicolumn{1}{c}{ Applications } & \multicolumn{1}{c}{ Experiment Loops } & Experiment Capsules \\
\hline Sodium-cooled Reactors & Sodium & $\begin{array}{l}\text { Sodium-filled or } \\
\text { Dry }\end{array}$ \\
Water-cooled Reactors & Steam or & Water \\
& Water & \\
Gas-cooled Reactors & Helium & None designed \\
\hline
\end{tabular}

Flowing-coolant loops (for prototypic, multiple-effects, complex interaction tests) are typically used in the TREAT reactor. A summary of the types of flowing coolant loops used or designed for TREAT include:

- Recirculating coolant ("package" style, or with part of loop outside the core)

- Once-through coolant (most of loop outside the core)

- Capsules, (for "phenomenological," "separate-effects," basic process tests)

- $\quad$ Gas-filled (dry)

- Stagnant liquid coolant

- Other configurations (e.g., for experiments with no reactor fuel).

Figure 5 shows a schematic depiction of two flowing coolants loops designed for TREAT, a flowing sodium coolant loop, and a steam recirculating loop. 


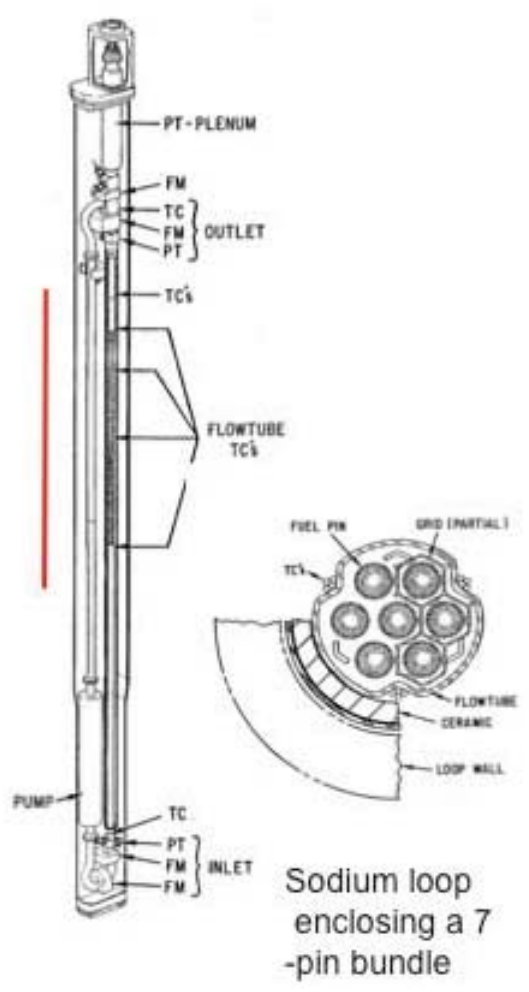

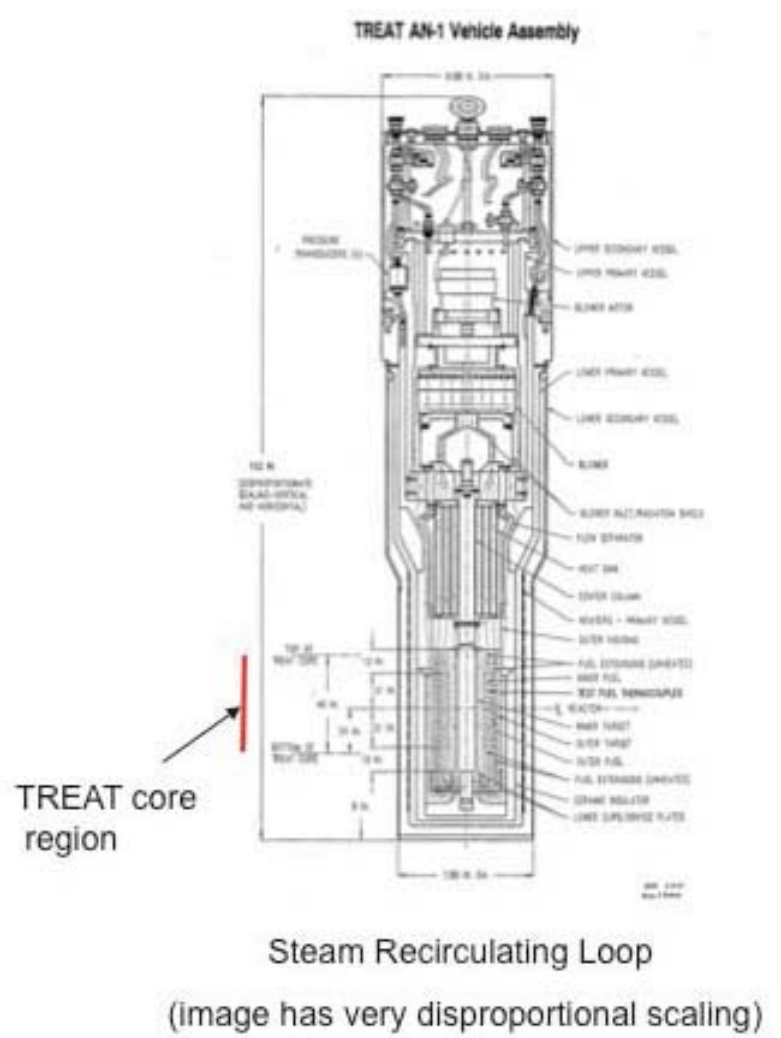

Figure 5. Two types of TREAT experiment loops.

Because TREAT core elements (fueled elements, un-fueled graphite elements, slotted elements, etc.) can easily be moved in and out of the core, the core can be loaded to accommodate a variety of sizes and shapes of experimental assemblies. The largest test vessel run to date occupied 214 -in. ${ }^{2}$ fuel positions, and the smallest occupied a single fuel position. Access to the core from above is limited by the $60-\mathrm{cm}$ diameter hole through the rotating plug above the core, and by the hook-height of the overhead crane. Access to the core from the north and south faces of the reactor is also possible. For many experiments, the hodoscope occupies much of the north face. Below the core grid plate (located about $2 \mathrm{ft}$, or $0.6 \mathrm{~m}$ below the core), there is limited additional space for experiment hardware to extend. Many of the test vehicles that have been used in TREAT can test more than one fuel pin simultaneously (e.g., in multi-pin bundles or with pins in separate flowtubes). For example, the Mark-III sodium loops, which are high-pressure stainless steel vessels and occupy two fuel positions, are capable of testing up to seven LMFBR-type fuel pins. Large areas for experiment hardware exist on top of the reactor, on the reactor building floor near the reactor, or in the mezzanine area of the reactor building adjacent to the top of the reactor. A variety of utility services are available for experiment support, including electrical power sources, cooling water, and gas systems.

The TREAT facility provides a unique combination of reactor capabilities, support services, and personnel to support a reactor fuel-testing program.

The Transient Reactor Test Facility (TREAT) has a long history of successful testing of a range of fuel types. A full range of fast reactor fuels was tested (both oxide and metal) and tests were also conducted on a variety of thermal reactor fuels. The power deposition achievable in experimental fuels will vaporize fuels, but most of the tests were conducted to better understand the progression of fuel failure under severe transient conditions. Accordingly, a range of transient conditions, power deposition, and peak temperatures was explored. One of the more important questions for new fuels is how well fuel 
behavior is understood for high-temperature conditions at the threshold of failure and such tests are typical of TREAT testing in the past.

High quality data collection is important to understanding behavior under such severe conditions and several novel instruments were developed at TREAT for this purpose. Principal among them was the neutron hodoscope that provided real-time imagery of the movement of fuel during failure. The opportunity exists to improve this instrumentation and the data collection associated with it given advances in technology over the last 2 decades.

TREAT relies on the large heat capacity of the graphite in the core to accommodate the heat deposited during transients and requires substantial time between tests for cool-down. Therefore, successive transients on a given fuel specimen can take days, depending upon the powers involved. However, there is limited capability for pre-transient conditioning of the test specimens prior to transients. The highest temperature achievable depends on the experiment containment, typically with refractory materials on the inside and high-strength material on the outside. This is an important capability since the behavior of fuel at very high temperatures is an important need for future testing and modeling.

\subsection{TREAT Testing: Specific Goals, Techniques and Useful Results (Ted Bauer)}

A family of tests is required to obtain a coherent picture for off-normal fuel performance and analysis. This requires a range of transient speeds and peak power in transients as well as preconditioning at steady power. Ideally, a combination of test facilities is required, such as was the case with TREAT and Experimental Breeder Reactor (EBR-II). (Operational transients were conducted in EBR-II at rates, which overlapped the lower bound of ramp rates possible in TREAT). An advantage today is that instrumentation and data analysis is much more sophisticated than existed during the earlier use of TREAT. Another advantage is the availability of considerable experience and data from previous experiments that can be analyzed and used to design improved instrumentation and testing sequences, speeding the process of experiment design and analysis. One trade-off may be that to obtain detailed information sufficient to support the modeling goals, more narrowly designed tests will be necessary, as opposed to the integral effects tests typical of the previous TREAT testing. A likely approach to testing will be to start with conservative tests, namely slower transients with single pins, working toward the more aggressive and expensive integral transient tests as models are improved.

Fuel performance and safety issues developed from postulated off-normal scenarios depend, not only on reactor design, but also on fuel-type, burnup, and location within the reactor core. Given the generic limitations of a "pulse"-type reactor with limited in-core volume available for experimentation, prototypic safety-related information obtained from a single TREAT simulation is limited to a finite space and time "slice" of a proposed accident scenario. Most commonly, past TREAT tests have:

- Simulated a segment of postulated accident power and coolant flow

- Detected cladding failure threshold

- Tracked material motions over a time interval immediately following cladding failure

- Determined power required to melt fuel.

Families of tests are required to obtain a coherent picture for accident analysis. Figure 6 and Figure 7 provide example results from transient testing in the TREAT reactor. TREAT test results spanning key time-slices and prototypic reactor core locations have been important elements of coherent accident analyses and understanding of fuel behavior and performance. This required multiple experiments, which covered a range of transient speeds and peak powers, as well as thermal "preconditioning" at steady power. 
Power-to-Melt Determination of the Thermal conductivity of Irradiated and restructured Metallic Fuel

[Bauer and Holland, 1995]

Pins subjected to overpower testing

- Posttest analysis of fuel melting observed in damaged but intact metallic fuel pins

Melt-fraction of cross section measured for different fuel compositions and locations

- Peak power deposition in test and average position of melt-front permits measurement of fuel thermal conductivity

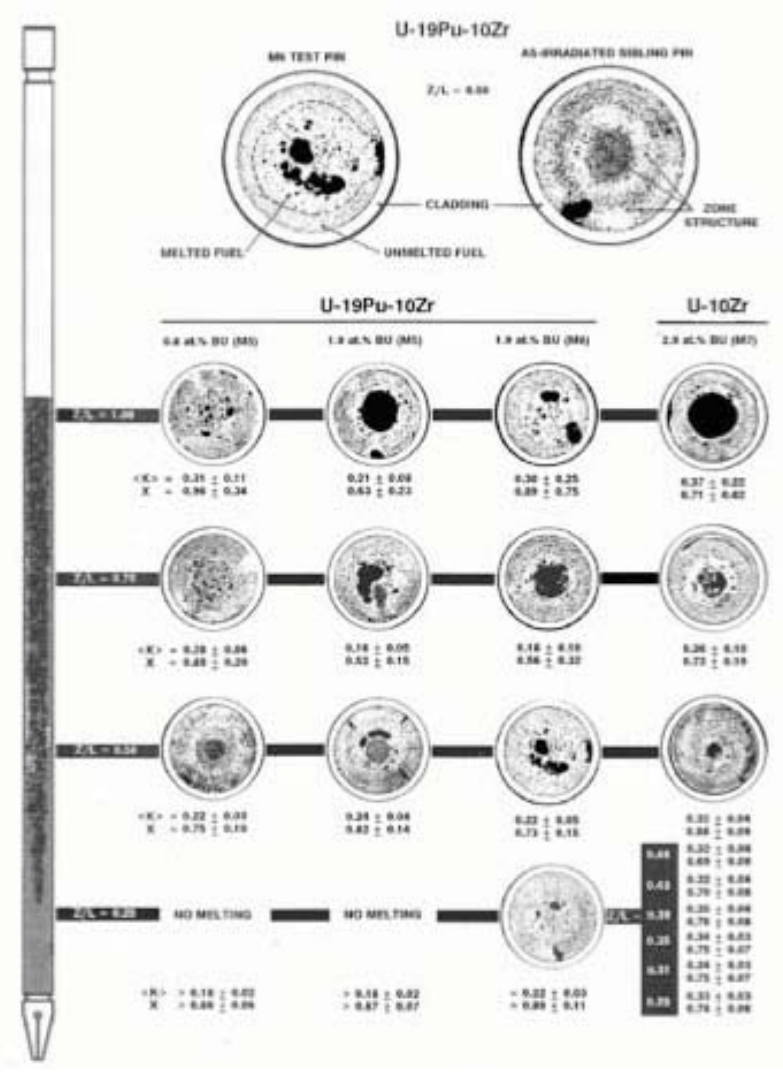

Figure 6. Example results from TREAT power to melt determination. ${ }^{\mathrm{i}}$

Transient Overpower Failure modes of Irradiated Metallic Fuel Pins

[Bauer et al., 1990]

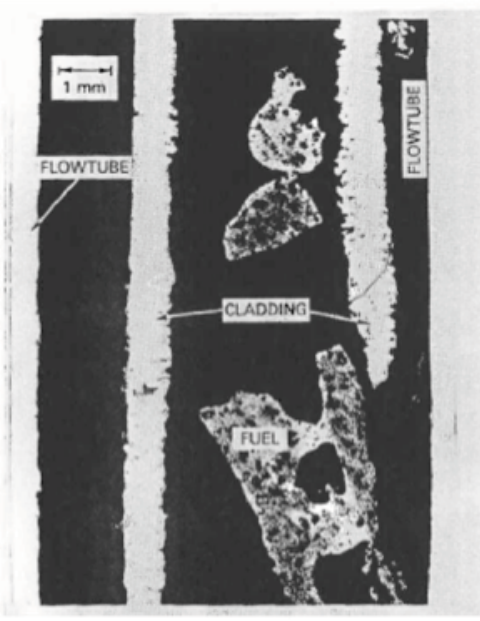

Dissolution and penetration of cladding by U-Fe eutectic

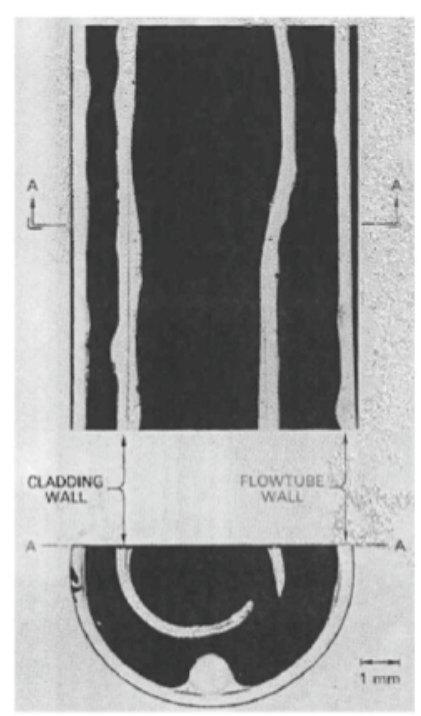

Cladding ballooning and rupture from pressure loading

Figure 7. Example of fuel failure mode determination results ${ }^{\mathrm{ii}}$. 
A coherent testing program in TREAT will likely utilize combinations of relatively simple (less expensive) tests of single pins. These could be followed by complex (more expensive) multi-pin, multi-effect "integral" tests, as needed. Additionally, experience with TREAT and EBR-II showed that coordinated results from multiple test facilities added significantly to enhance the picture of safety-related fuel performance and forward the understanding of fuel behavior and performance. (Operational transients were conducted in EBR-II at rates that overlapped the lower bound of ramp rates possible in TREAT.)

A clear advantage today is that instrumentation and data analysis can be much more sophisticated than existed during the earlier use of TREAT. The considerable experience and data from previous experiments (that can be analyzed and used to design improved instrumentation and testing sequences) also speeds the process of future experiment design and analyses.

\subsection{Transient Testing Support Infrastructure in HFEF (Greg Teske)}

HFEF was specifically designed and built to support post-irradiation examination of nuclear fuels, especially those irradiated in EBR-II and TREAT. The Hot Fuel Examination Facility (HFEF) also supports experiment operations in TREAT including pre and post-processing of experimental test loops. It prepared TREAT experiments for testing in TREAT, and then provided for disassembly and posttest examination of fuel experiments from TREAT. A photograph of a partially disassembled TREAT loop is shown in Figure 8.

Figure 9 provides a summary of the materials handling capabilities in HFEF that are needed for handling TREAT loops. Figure 10 provides a summary of the non-destructive post irradiation examination capabilities provided in HFEF applicable to the study and analysis of TREAT loops.

HFEF provided full services, emphasizing Post-Irradiation-Examination (PIE), which included use of the TRIGA reactor as a Neutron Radiography Reactor (NRAD) facility. Figure 11 provides a schematic representation of the HFEF NRAD facility. Spent fuel from the tests is stored at an onsite facility-the Radioactive Storage and Waste Facility (RSWF). Experimenters, however, must retain ownership of the material for ultimate disposal.

HFEF capability is currently being upgraded with the installation of state-of-the-art examination equipment associated with a variety of programs that utilize the facility. It is maintained as a very clean facility and is fully operational. 

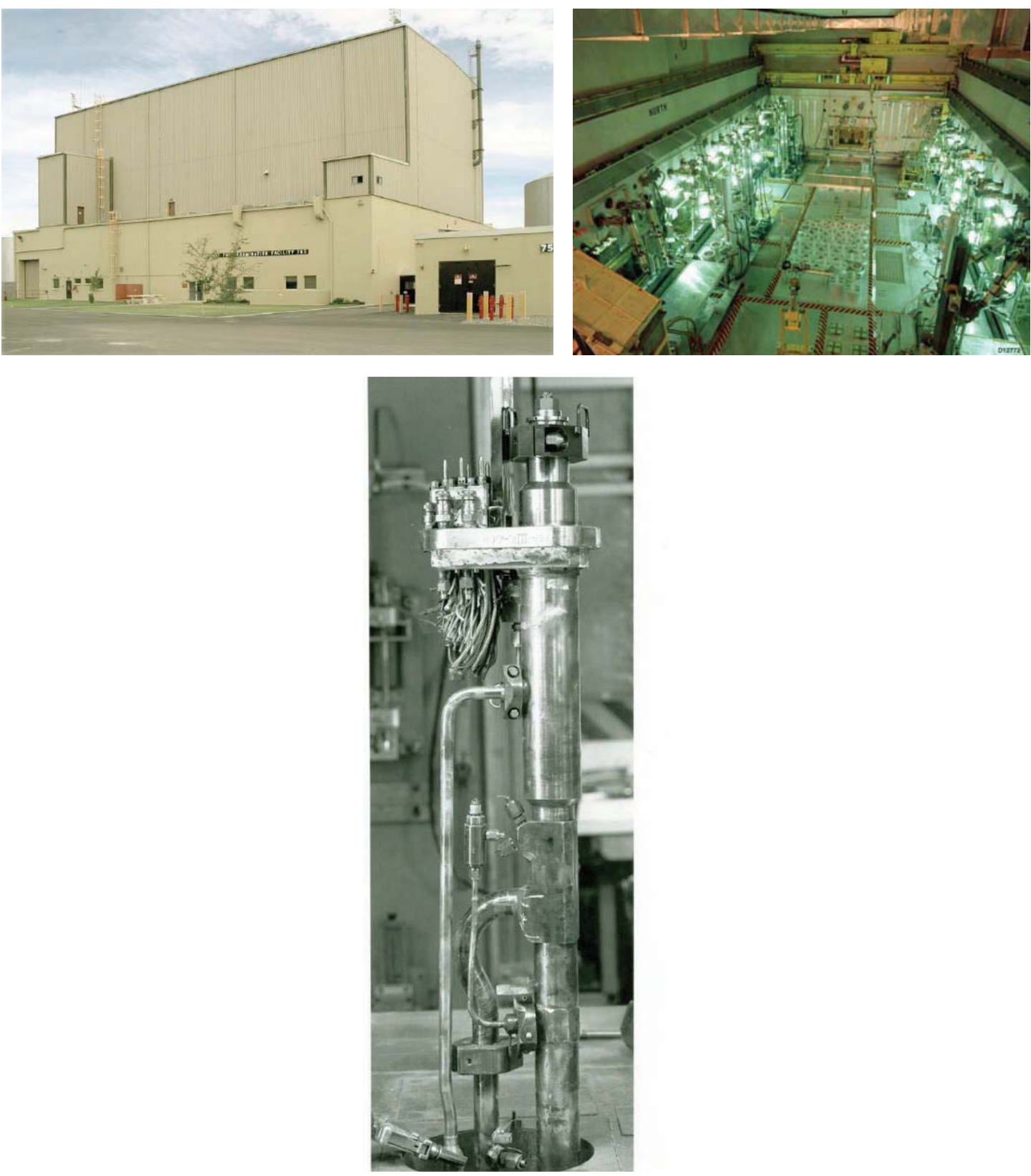

Figure 8. Stripped sodium loop photographed in the HFEF hot cells. 


\section{HFEF Material Handling Systems}

\section{- Capability}

- Shipping casks up to $29 \mathrm{t}$ and $1.4 \mathrm{~m}$ diam. $x 5 \mathrm{~m}$ long via cask tunnel

- Fuel assemblies and reactor experiments up to $0.5 \mathrm{~m}$ diam. $\times 4 \mathrm{~m}$ long via cask tunnel

- Reactor experiments up to $0.6 \mathrm{~m}$ diam. $x 8 \mathrm{~m}$ long via insertion cell

- In-cell equipment up to $4.5 \mathrm{t}$ and 1.75 $\mathrm{m}$ diam. $\times 3.6 \mathrm{~m}$ long

- $340 \mathrm{~kg}$ capacity servo manipulators

- 21 large $(3 \mathrm{~m} \times 3 \mathrm{~m})$ work stations

- Shielding windows and hand operated manipulators at all work stations

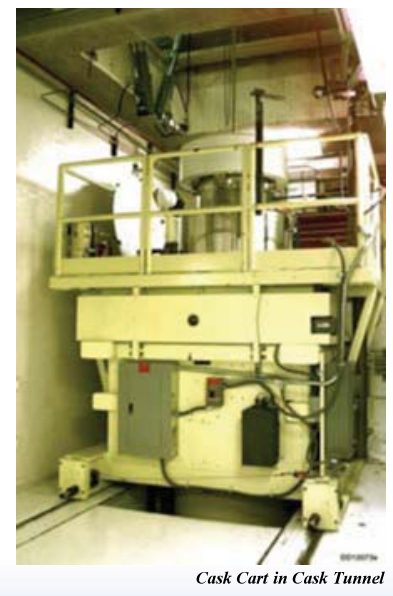

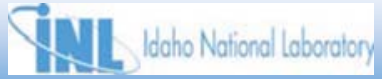

Figure 9. HFEF material handling systems.

\section{HFEF Non-Destructive Examinations}

\section{- NDE Capabilities}

- Diameter measurements

- Length measurement

- Weight measurement

- Fission/activation product distribution via precision gamma spectroscopy

- Visual exam

- Macro photography

- Neutron radiography

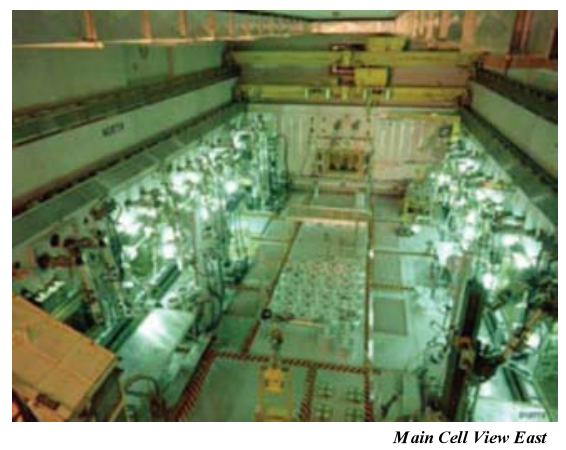

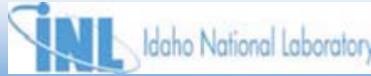

Figure 10. HFEF non-destructive examinations. 


\section{HFEF Neutron Radiography Facility}

(NRAD)

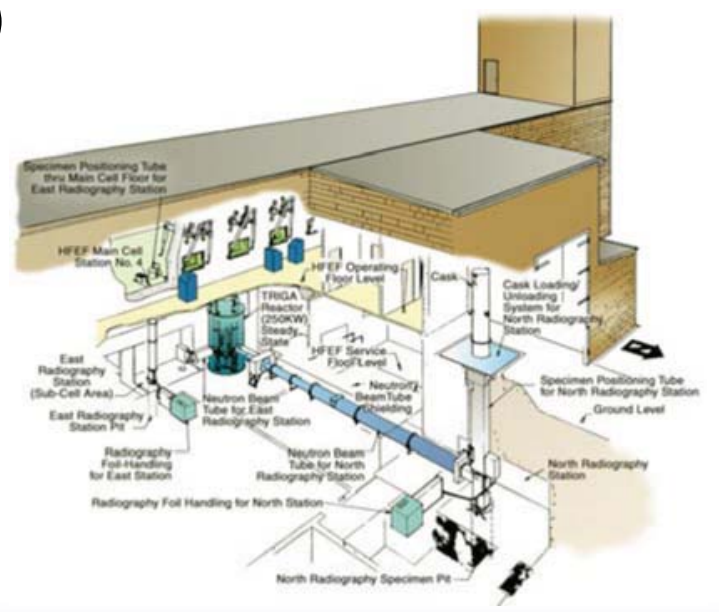

\section{Idaho National loboratory}

Figure 11. HFEF Neutron Radiography Facility. 


\section{CURRENT STATUS OF TRANSIENT TESTING PROGRAMS AT CEA AND JAEA}

\subsection{Status of CABRI (Phillipe Dufour)}

The CABRI facility is a fully functional transient test facility located at Cadarache, France (see Figure 12). It is similar in function to the TREAT facility but has a fundamentally different driver core design and is water-cooled (in contrast to TREAT, which is air-cooled). It has conducted significant transient tests on a variety of nuclear fuel systems and is currently configured with a light-water reactor (LWR) coolant loop experimental capability. The schematic shown below depicts the CABRI facility showing its facility layout with core, coolant, and water test-loop configuration.

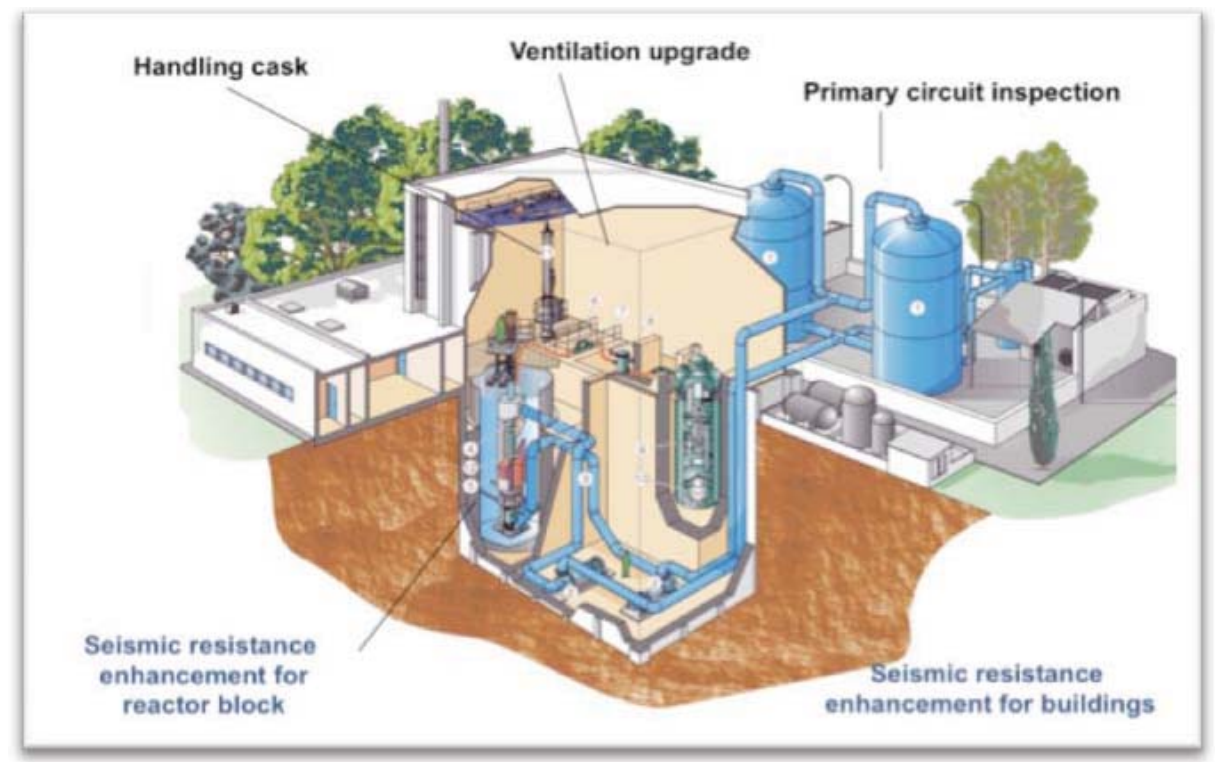

Figure 12. Schematic of the CABRI Facility (Cadarache, France).

CABRI has implemented an interesting instrumentation technique for detecting and locating fuel failure during the transient experiment using acoustic microphones. This technique should be investigated for implementation in TREAT experiments.

Past CABRI programs have common objectives with those of TREAT and future transient testing. A full range of fuel tests have been conducted with emphasis on fast-reactor fuels. There were four major programs conducted from 1978 to 2001 to investigate the behavior of fast reactor fuels under transients. Fifty-nine experiments were conducted in a sodium loop, addressing fuel for SuperPhenix and Phenix. Tests were also conducted in support of fuel development for Pressurized Water Reactors from 1993 to 2000. Both $\mathrm{UO}_{2}$ and mixed oxide (MOX) pressurized water reactor (PWR) fuel rods were conducted as part of an international program. This work established the safety criteria applied today; new tests would further evaluate those criteria and improve understandings of safety margins in advanced fuels.

CABRI has an associated hot cell, LECA, which is similar in purpose and capability to the HFEF. The CABRI core is being upgraded to correct some degradation of the fuel. There is no plan to conduct tests in support of a new sodium-cooled reactor, but there are plans to conduct further tests of LWR fuel. 


\subsection{Status of NSRR (Ikken Sato)}

The NSRR transient facility (shown in Figure 13) is similar to the CABRI facility, but it is smaller. It is dedicated to the study of LWR fuel systems in transient experiments. It is a pool-type pulse reactor utilizing water for coolant.

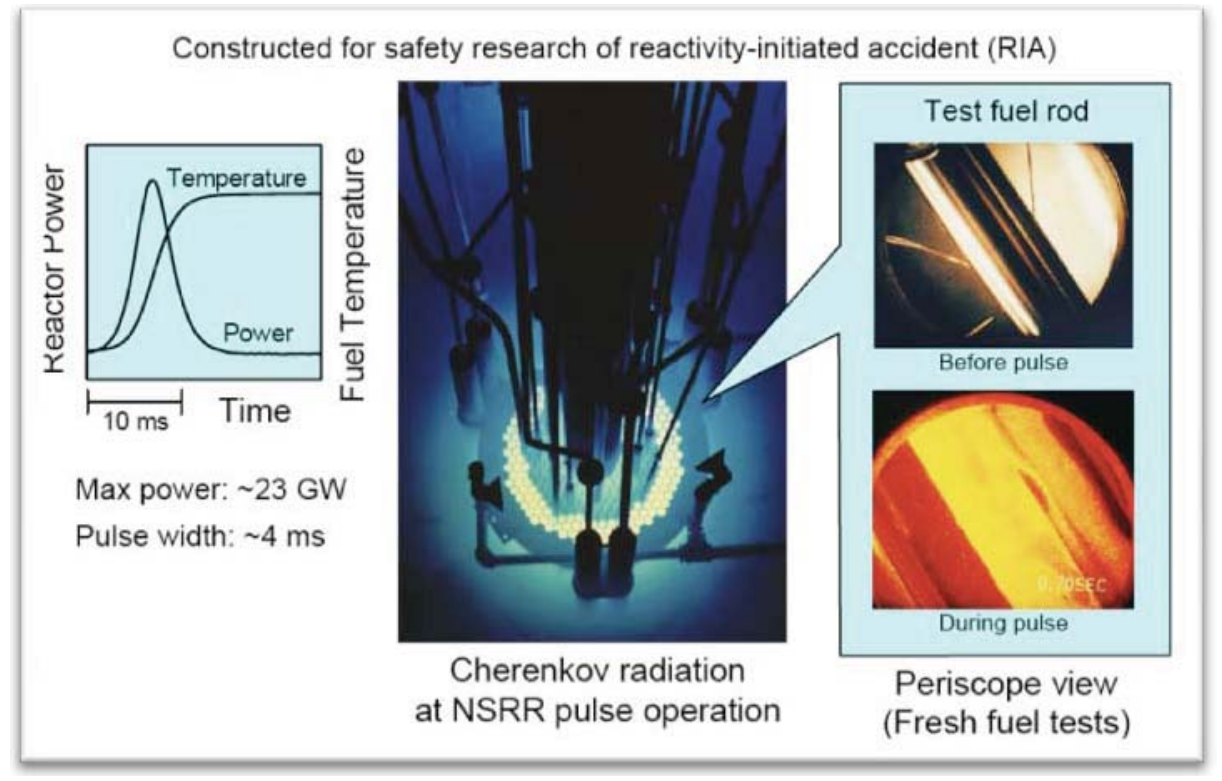

Figure 13. NSRR transient facility operated by JAEA in Japan.

The NSRR pulse test reactor is a modified TRIGA-annular core pulse reactor (ACPR) with capabilities similar to the Sandia Annular Core Research Reactor. JAEA has performed pulse-irradiation experiments, which simulate reactivity-initiated accidents at NSRR since 1975. Over 1,200 tests with fresh LWR fuel rods and more than 80 tests with high bump rods have been carried out. The results were reflected in Japanese safety regulatory guides for Reactivity Initiated Accident (RIA). Further safety researches using NSSR are expected to support fuel burnup extension and MOX fuel introduction. In order to meet the requirement, the capability of NSRR facilities is being extended. Because of the configuration and water coolant, experiments can be observed by optical means before and during the transients. Transient tests have been conducted since 1975 .

Reactor core parameters are as follows: Effective height: $\sim 38 \mathrm{~cm}$, Equivalent diameter: $\sim 60 \mathrm{~cm}$, Moderator: $\mathrm{ZrH}, \mathrm{H}_{2} \mathrm{O}$, Driver fuel rod, Fuel materials: U-ZrH1.6, Enrichment: 20\%, Cladding: SUS 304, Dimensions: $3.75 \mathrm{~cm}$ diameter $\times 60 \mathrm{~cm}$ long, Number of rods: 157 .

Fuels subjected to the NSRR experiments include:

- $\mathrm{PWR} / \mathrm{UO}_{2}(14 \times 14,17 \times 17$ arrays $) 34$ tests

- PWR/MOX $(14 \times 14$ arrays $) 3$ tests

- $\mathrm{BWR} / \mathrm{UO}_{2}(7 \times 7,8 \times 8,10 \times 10$ arrays $) 18$ tests

- $\mathrm{BWR} / \mathrm{MOX}(8 \times 8$ arrays $) 1$ test

- ATR/MOX 6 tests

- JMTR pre-irradiated $\mathrm{UO}_{2} 22$ tests. 
JAEA has performed many pulse-irradiation experiments, which simulate RIAs, at NSRR since 1975. Over 1,200 tests with fresh LWR fuel rods and more than 80 tests with high burnup rods have been carried out. Japanese safety regulatory guides for RIA reflected these results. Further safety researches using NSRR are expected to support fuel burnup extension and MOX fuel introduction. In order to meet the requirement, the capability of NSRR facilities is being extended. 


\section{A SCIENTIFIC APPROACH TO TRANSIENT TESTING (GEORGE IMEL)}

During the Transient Testing Workshop, the questions of why and when transient testing is needed were addressed, including the role of TREAT. The answer is that the new fuel/clad combinations being proposed will require testing, for the same reasons that such testing was important for existing fuels. TREAT is especially valuable for many reasons, one of which is that transient shapes can be easily programmed. The facility is very accessible for experiments and can accept a variety of experiment and instrument configurations. It is easy to install test loops of many different designs. The opportunity to design and install new sophisticated instrumentation exists, one of the most important being the hodoscope, which takes advantage of an open slot to the core. There is also an opportunity to design optical imaging. In short, because of TREAT's versatility it is not so much a question of what TREAT has, but what the experimenters need.

Advances in instrumentation have created many new opportunities for science-based testing. In-core instrumentation that was not possible a few years ago can now be installed, fission chambers can be placed adjacent to the tests, and high-temperature thermo-couples are available. Optical line-of-sight detectors are also possible, which could yield valuable information on fuel and cladding movement during transients.

The conclusions from this workshop are that transient testing is very much needed to support the design of advanced fuels, the opportunity exists to generate data to support detailed modeling of fuel performance, and the versatility of TREAT is ideal for this testing. Detailed data from a carefully constructed testing program will support a science-based approach to fuel performance modeling. 


\section{DESCRIPTION OF HISTORICAL TREAT INSTRUMENTATION (KEVIN CARNEY)}

Dr. Kevin Carney provided a detailed presentation during the workshop focusing on the capabilities of the hodoscope neutron detection and measurement system implemented on the TREAT reactor. Figure 14 provides top-view and side-view schematics of the hodoscope system.

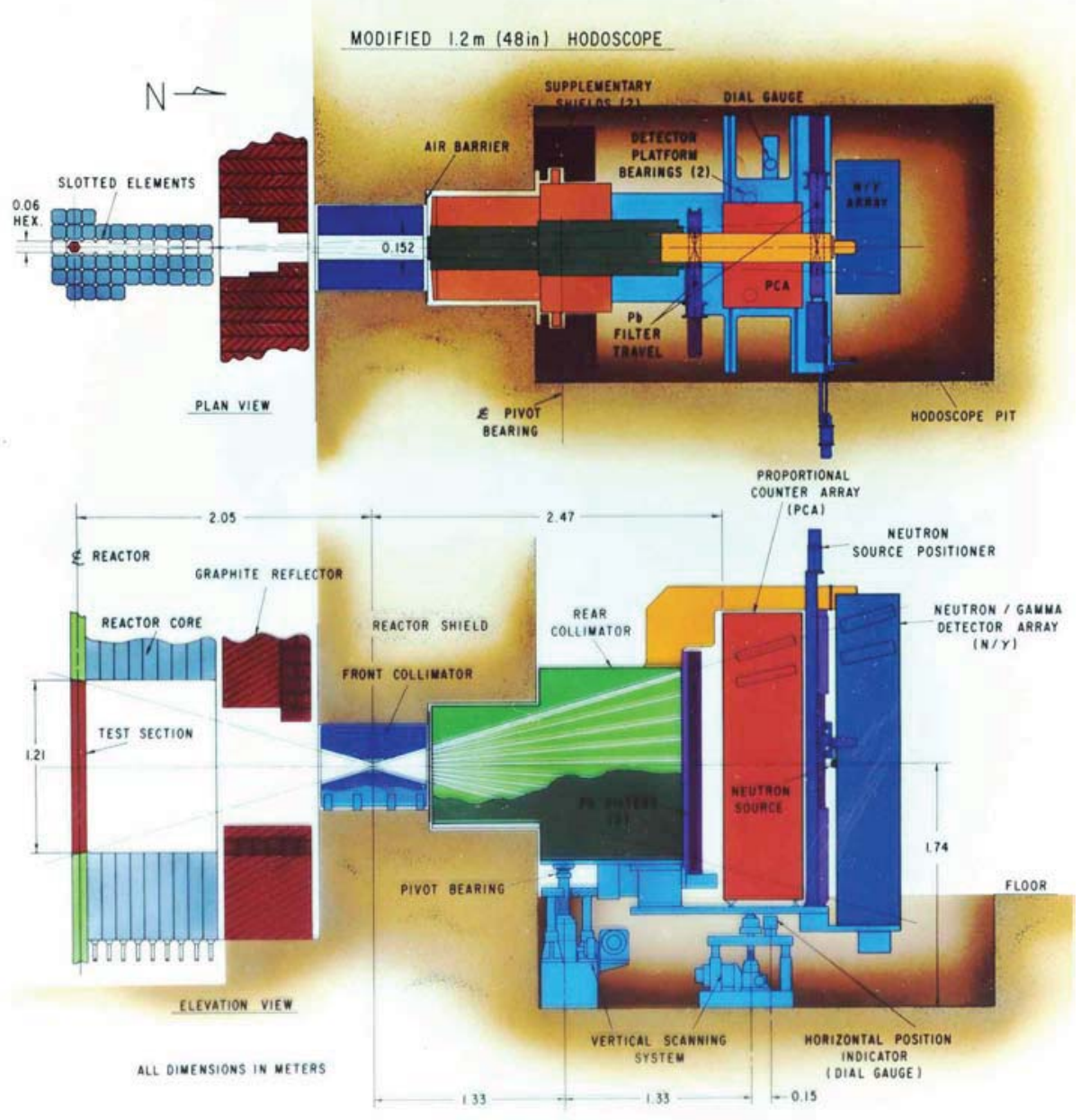

Figure 14. Schematic of the TREAT hodoscope.

The hodoscope functions as a method of measuring the test fuel motion experienced during the conduct of a transient experiment. Figure 15 provides an example of the type of information that is generated from the analysis of hodoscope data. In the figure, the successive images show the time progression of fuel density in each hodoscope pixel in a test in which two fuel pins were located side by side. The pin on the left side, which did not fail during the test, was aligned with a column of hodoscope pixels; the pin on the right side, which did fail, was located in the area viewed by two adjacent columns. In general, the mass resolution obtained using the hodoscope is, at best, 0.2 grams of fuel per channel for single-pin experiments and 0.8 grams of fuel per channel for 7-pin experiments. It is generally accepted that future experimenters and experiments will desire even higher resolution hodoscope data. 

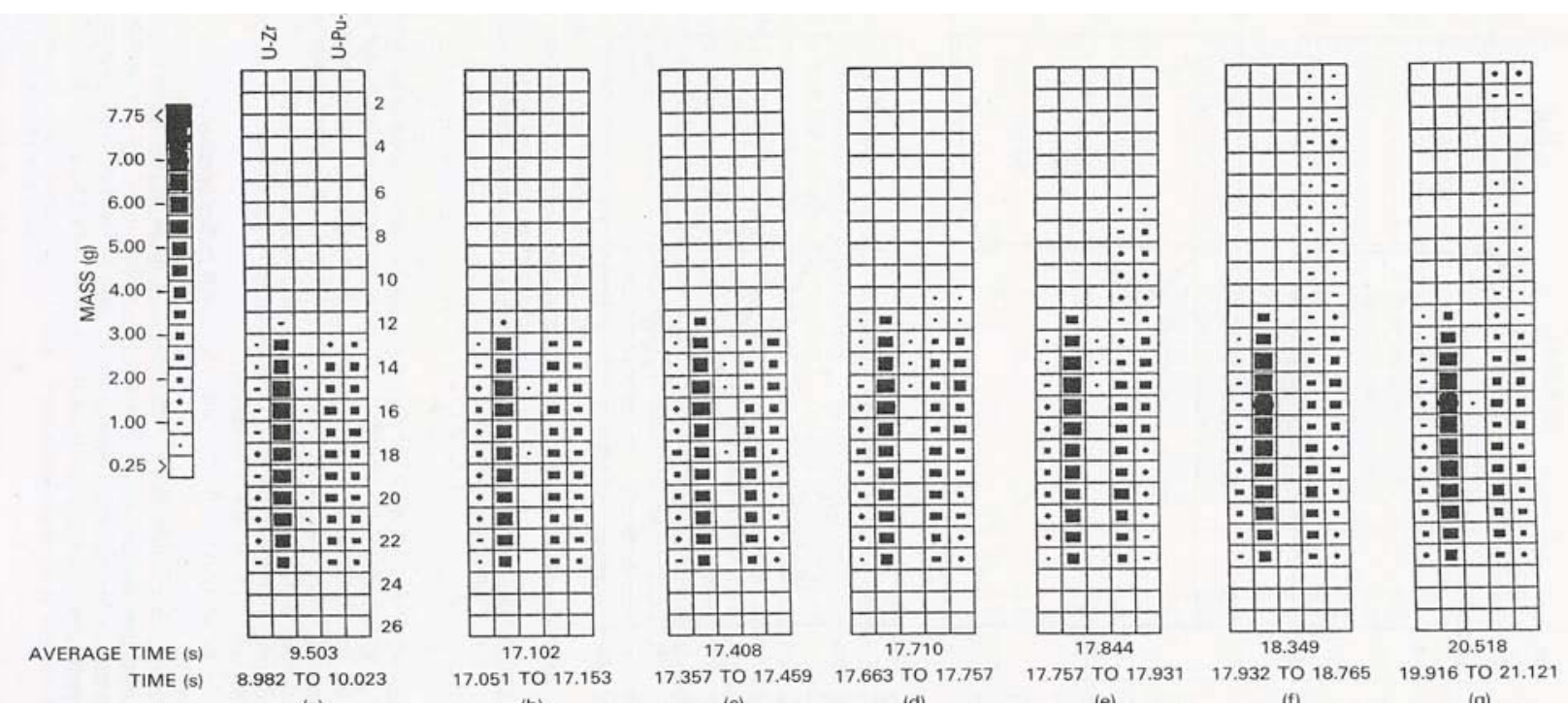

Figure 15. Example of analyzed TREAT hodoscope data (fuel motion with time).

Customer needs drive test designs and instrumentation needs (e.g., dimensional tolerances and ranges). Viewing the whole fuel element or just a segment is desirable. In addition, redundant data acquisition systems are important to ensure that no data is lost. The flexibility of the TREAT hodoscope can accommodate a number of experiments. Since operation of the TREAT hodoscope, other neutron detection programs have developed exciting detection techniques that may have applicability to TREAT allowing higher special and temporal resolution.

The following section provides a discussion of the general state of the art in neutron detection. Neutron detection has progressed since the operation of TREAT and the development and operation of the hodoscope system. Future transient testing requires higher resolution data from the neutron detection systems and should be provided for in planning for future transient testing. 


\section{IMAGING OF DYNAMIC SYSTEMS AND FUTURE INSTRUMENTATION DEVELOPMENT (KEVIN CARNEY)}

There is a desire to obtain higher fidelity information from future TREAT reactor experiments. The neutron hodoscope in place at TREAT was used to provide experimental fuel mass measurements with a resolution just below a gram per channel. Upgrades to this system, which include modern detectors and/or data acquisition system equipment, could provide higher precision measurements and prove to be a worthwhile investment. However, technology on both those fronts have evolved considerably since the design of the current hodoscope and it may be a good time to reconsider the experimental approach. A lively discussion took place during the "Instrumentation Development" session of the workshop to discuss the possibilities. The attendees were asked to provide suggestions as to the types of data they would like to garner, without regard to experimental limitations, from an upgraded TREAT reactor. There were also some discussions on some of the "possibilities" for delivering, or beginning to deliver, this data. There was also discussion of non-traditional types of measurements at TREAT that could take advantage of the direct view of the specimen volume.

The current TREAT capabilities provide coarse information about fuel behavior at the end of irradiation or under transient conditions. Motion pictures and hodoscope data provide valuable integral information about bulk fuel motion under these extremes. Higher resolution measurements with finer granularity have been requested and can be carried out, to some level, with incremental refinements of the current hodoscope. Relatively simple upgrades to the neutron detectors and a more robust data acquisition system could provide refined data. However, there is a limit to the achievable resolution that can be obtained using neutrons, given the experimental conditions and sample thicknesses. The inclusion of gamma detectors could also prove to be useful in some running modes, in an expanded data stream, and could also provide a path forward to finer granularity measurements. Multiple-axis views and time correlations may provide tomographic information about energy production profiles, mass flow, and potential fission product migration (between pulses). However, the primary limitation will be the gamma flash, which can only be partially addressed, broadly speaking, with modified operation, so experimental and detector development will be necessary to achieve this particular upgrade.

In the meeting, other types of information were identified as useful that may be considered macroscopic, such as pressure, surface temperatures, stress, strain, microphonics, coolant flow, buckling and bending. Techniques exist for these types of measurements but may have to be adapted to the reactor TREAT environment. Considerations should be made as to the value of these types of measurements with higher granularity and resolution to justify further specific detector development. These types of highresolution experiments will also require spatial measurements of the neutron field in the irradiation volume to insure that fluence dependency is understood. The ability to model the neutron flux in the TREAT reactor with the appropriate level of detail will be important to not only understanding results from experiments, but will be invaluable for experiment design. This is a development project in its own right and will have to be addressed. Fortunately, there is plenty of synergy for this effort given the broad need for better neutron detection in many other programs, offices, and departments, not to mention international needs.

In the past, experiments were carried out using full-sized fuel pins and assemblies. An expanded program to include smaller experiments could prove invaluable in an effort to understand fuel behavior under radiation and advance the state-of-the art modeling. The idea is to use small experiments that are easier to model than full assemblies and designed to provide details of the fuel meat and cladding behaviors under non-standard but simplified conditions. This synergy has the potential of accelerating the fuel simulation effort while providing less-complicated experimental conditions. This type of effort would allow experimentalists to not only provide extremely useful data early on, but to have the necessary time to develop the more complicated tools required to deliver these types of data from larger assemblies. One 
could argue that if the right set of small experiments were completed and faithfully modeled with a code containing enough basic physics, the need for full-up high resolution experiments might be eliminated. The value of this approach is that this decision follows naturally from the smaller experiments and does not have to be made up front. 


\section{EXPERIMENTAL STUDY AND SIMULATION FOR A VERY FAST TRANSIENT EVENT FOR MATERIALS BEHAVIOR (CETIN UNAL)}

A driving need behind the future transient testing is to develop a detailed microstructure understanding of nuclear fuel behavior under possible operational conditions, including transient conditions. A primary goal of current nuclear system research and development is to build tools that have the capability to provide predictive simulation of fuel and materials behavior at a micro-structural scale. This requires that an understanding be developed and tested at this scale. Simulations will also require validation at this scale.

Dr. Unal presented a study on the "Modeling and Simulation of Material Behavior under Explosive Loading - Dynamic Fracture and Spallation in Ductile Solids in Fast Transients". The purpose of his presentation is to demonstrate how we can make use of a combination of small-scale experiments and modeling and simulation to study important phenomena that affect the performance of a system. His example concentrated deliberately on a nation's stockpile problem that involves the development of a material strength model. The example had several interesting parallels with TREAT capabilities and the need for TREAT to support this type of model development for nuclear fuels and materials.

The analytical problem selected was the dynamic fracture and spallation in ductile solids. The spallation in ductile materials is controlled by localized plastic deformation around small voids that grow and eventually coalesce to form the spall plane. Neither plate-impact nor explosively-loaded cases require statistical treatment of the various material elements in a calculation. This particular subject is relevant to crack formation in the fuels and clad. The damage and strength models are of interest in terms of fuels applications. A set of different testing in TREAT can be designed to support NEAMS fuels program.

Dr. Unal emphasized the importance of an integrated M\&S approach in which code development, experiments, model development, and $\mathrm{V} \& \mathrm{~V}$ and $\mathrm{UQ}$ is included into a single programmatic structure. His example was from weapons ASC programs and Science Camping and V\&V QMU projects.

When a pressure wave produced by a high-explosive (HE) detonation reaches the free surface of most metals, different phenomena can occur: (a) one or more layers of solid material is produced from the fracture of the metal and accelerated ("spall") or (b) the metal is melted on release and accelerated to fairly high velocities. The detailed understanding of damage and spall phenomena in metals is an active area of research in shock physics but also in materials science and microstructural modeling and is of significant interest to both applied and basic science. Dr. Unal presented an example of data obtained from proton radiography (PRad) experiments to study HE-induced spall in several metals. These experiments used the PRad facility in Area C at the Los Alamos Neutron Scattering Center (LANSCE).

The basic configuration of the experiment included a test specimen that had a 0.5 -in.-thick cylinder of HE (PBX 9501) that is initiated with an SE-1 detonator centered on the charge. Because the HE is point initiated, the shock wave has significant curvature. This curved geometry may be advantageous in PRad experiments since the integral of the proton path length is often shorter, and resolution and contrast may be improved, as compared to a pure planar geometry. A velocity laser interferometer (VISAR) is also used to measure the time history of the surface during the experiment. Excellent agreement between VISAR and radiography results for the free surface velocity was obtained in all experiments to date. The "shutter time" of these proton radiographs is determined by the pulse width of protons that are used to produce each image frame. In these cases, the pulse width was typically less than $50 \mathrm{~ns}$, a short enough time to produce minimal motion blur $(\approx 100 \mu \mathrm{m})$ even for the highest material velocity (aluminum at $\sim 2 \mathrm{~km} / \mathrm{s})$. 
In another example he showed explosive tests including five tests at pRad using $40 \mathrm{~mm}$ and $80 \mathrm{~mm}$ diameter, $1 \mathrm{~mm}$ wall thickness hemispheres filled with explosives. The first shot was $80 \mathrm{~mm}$ steel. The rest were U6 "picture frame" material. The HE is initiated by a radiographically thin slapper at the center. The pRad pictures indicated that Steel behaves with much more ductility than Uranium Niabium alloy, and so these images extend later than the U6 data with the same amount of damage having experienced the same drive. In this example he emphasized that a great deal can be compared, but more must be accounted for percent open area, number of cornflakes per unit area, size of cornflakes, function of threshold, function of distance from detonator. However, applying these metrics to static shots finds uncertainties that are too large to identify a trend. He concluded that there is a need to understand and remove shot-to-shot variations, data-scanner variations (and dealing with proprietary information), and beam anomalies.

During his discussion he emphasized the need to change "in box" thinking and think about how to modify TREAT facility to provide high resolution, faster capabilities, such as those that pRad technique provides to obtain fuels data for M\&S validation. The ACS capabilities can be used to model melting behavior of the fuels. Present NEAMS fuels M\&S effort does not consider severe accident management. Modeling of the melt behavior (flow blockage) is not NEAMS scope. The ASC codes can help in this area if severe accident management is an issue for AFCI licensing (currently LWR requires a plan for severe accident management, mostly THD and fluid melt interaction rather than core or fuel performance). Modeling of cracks in fuels and clad can benefit from ASC damage models, and some testing can be done in TREAT.

This presentation concluded with the suggestion on some TREAT experiments for fuels M\&S simulation validation work. The message was that we need to introduce new measurements techniques suitable to detect grain evolution and irradiation effects considering different geometries rather than the prototypical cylindrical geometry. The gas release strongly depends upon temperature and fuel microstructure $\left(\mathrm{D}_{\mathrm{Xe}}\right.$ is effected not only by grain size [GB concentration], but also GB structure). It is noted that the fuel models are developed from steady-state, long-term fuel irradiation tests. Adequacy of the use of steady state models in relatively fast transients are not examined and verified; gas release rate in the transients may not be predicted well with current models. The presentation emphasized that the determination of $\mu$-structural dependence evolution during transient and effect on gas release is an important aspect of new modeling approach. The comparison of the fresh to irradiated fuels (different burnups) is necessary to understand the $\mu$-structure dependence. The one way to study these effects to fabricate synthesized fresh fuel of different $\mu$-structures and study them under irradiation. We need to rely upon FFTF pins and ATR for different irradiation exposure to figure out the $\mu$-structure effects. Before insertion in TREAT, the $\mu$-structure of all samples must be established and characterized well in terms of microstructure statistics. These specially made fuels then are irradiated in TREAT in transient mode and re-evaluate microstructure. These tests should be done in a power-time scenario in which the fuel should not melt but temperature is increased above nominal values.

Dr. Unal also suggested some testing strategy for clad. It was noted that the crack formation is a key aspect that needs to be studied mechanistically as well as experimentally. There are several experiments we can design to help NEAMS fuel clad modeling; dose and temperature are key parameters for clad performance. We can perform pin failure experiment and determine the time and/or temperature of fuel/clad at the failure point. The determination of temperature and/or time right below the failure point is key and the same experiments can be run at that point. These experiments have to be repeated to identify at what temperature clad cracks are appearing. Experiments should be performed below crack temperature thresholds in a periodic manner to extend the exposure time. For each experiment, the characterization of fuel microstructures and properties is necessary. We suggest to consider fresh irradiated clads to test the microstructure effects on modeling (such as suggested in fuels). As new a way of looking at the clad problems, developing optical instrumentation can detect clad cracks so that the above experiments can be 
repeated in situ situation. These will enhance our modeling capabilities to predict the clad cracking at higher doses (temperatures) that AFCI fuels campaign is targeting.

In the question and answers section of the presentation, Leon Walter's indicated that he has not heard a safety discussion, a definition of initiating events to solve, or what phenomena going to address with tools. These things need to be defined either during or after the workshop. Dr. Unal's response was that the road map developed for M\&S included the phenomenon that needs to be modeled. Heather MacLean commented on the need to be studying phenomena in early stage to understand what fundamental interactions in fuel, etc., and need to address the unknown phenomena as well. She asked if he could at least start with defining/designing some early tests to address this. Dr. Unal said concentrating on fundamental understanding of phenomena in fuels is the priority. NEAMS is a $\$ 20 \mathrm{M}$ per year program for 10 years. We expect tools will be available to designers, and we need to identify the things we need to do perfectly (completing the sensitivity study first). 


\section{MODELING AND SIMULATION DEVELOPMENT NEEDS FOR TRANSIENT TESTING (DIETER WOLF)}

Hierarchical multi-scale simulation approach for predicting the performance, degradation, and lifetime of nuclear materials. The atomic-level approach sketched on the left usually involves moleculardynamics (MD) simulations in which the evolution of the system is followed based on the successive solution of Newton's equations of motion (typically over millions of time steps, or nanoseconds of real time). The quantified insights from these simulations provide the input to the mesoscale approach shown in the center. Rather than the atoms, the objects evolving in the mesoscale model are the microstructural elements themselves, such as the grain boundaries, dislocations, voids, fission gas-filled bubbles, etc. Instead of filling space with atoms (as in the atomistic approach), at the mesoscale space is discretized by a finite-element type of grid, in terms of which the material microstructure can be mapped. Also, by contrast with Newton's laws (according to which a force results in an acceleration), the mesoscale elements evolve via a viscous force law (according to which a constant force produces a constant velocity). The mesoscale simulation follows explicitly the evolution of the microstructure, typically over milliseconds of real time, under the assumed evolution mechanisms (such as grain-boundary and dislocation motion, surface, grain-boundary, void and fission gas-filled bubble motion, etc.).

\section{Hierarchical Multi-scale Simulation of Nuclear Fuel}

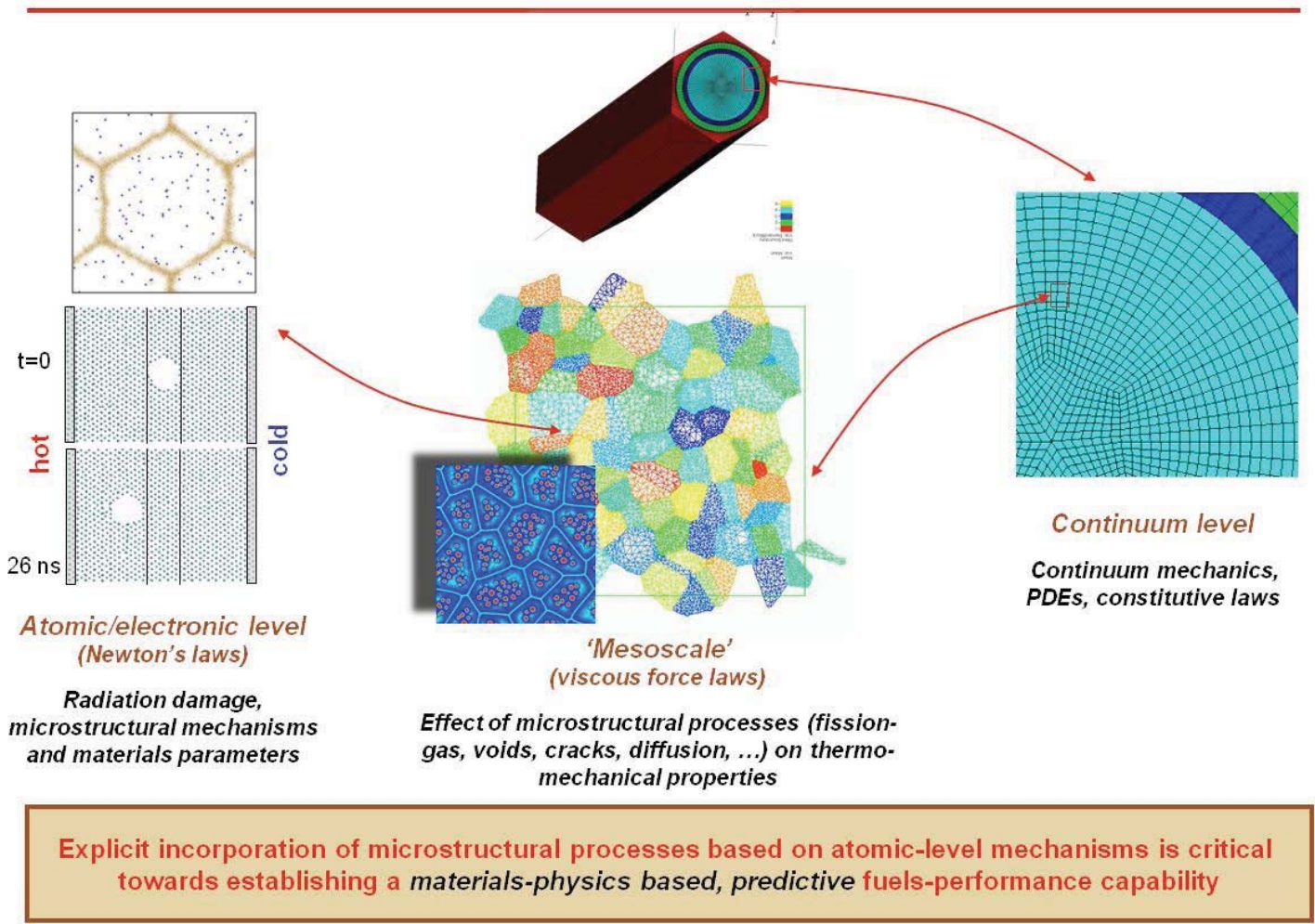

Figure 16. Hierarchical Multi-scale Simulation of Nuclear Fuel.

These processes are then available for input into the continuum-level approach sketched on the right. The continuum calculations usually involve solution of a coupled set of partial differential equations with materials input via empirical relations for the thermo-mechanical behavior of the material under the effects of irradiation. The bridging of the distinct time and length-scale regimes in this hierarchical approach will ultimately enable a predictive, materials-physics based description of the nuclear material 
under the effects of irradiation, internal and external stresses as well as temperature and stress gradients, and over realistic time scales for a real material. The specific graphs in this picture capture the following phenomena:

A. The snapshot in the top half on the left is taken from a simulation of the interaction between irradiation-induced vacancies and the grain boundaries in nanocrystalline molybdenum with a columnar microstructure. In addition to the diffusion mechanisms in the grain interiors and the grain boundaries, these simulations provide the associated activation energies as well as the vacancy sink strength of the grain boundaries, which are all needed as input to the mesoscale model. The simulation in the bottom half shows an MD simulation of a void in $\mathrm{UO}_{2}$ that moves under an applied temperature gradient. The two snapshots reveal the displacement of the void up the temperature gradient, from which the void mobility and the underlying migration mechanism (in this case, the surface chemical diffusion of $\mathrm{UO}_{2}$ ) can be extracted.

B. The mesoscale sketch in the lower center shows a discretized polycrystalline microstructure. The two superimposed highlights represent two snapshots obtained from an atomistically-informed phase-field simulation of the nucleation and growth of irradiation-induced voids (see Figure 16).

C. The continuum-level picture on the right exhibits a cross section through the fuel pin sketched on the top. The superimposed mesh represents the points at which the coupled partial differential equations are solved, and at which the continuum-level code can receive input from the mesoscale code. For example, this input consists of updated values of the thermal conductivity, elastic moduli, and thermal-expansion coefficient for a given burn-up and under the temperature and stress states passed down to the mesoscale from the continuum level. 


\section{SUMMARY OF NEEDS FOR TRANSIENT TESTING IN SUPPORT OF NUCLEAR ENERGY SCIENCE}

\subsection{Input from Light-Water Reactor Industry (Nam Dinh)}

Understanding and predicting fuel performance in LWRs are central to both sustainability of the existing fleet of LWR nuclear power plants and successful deployment of advanced LWRs (Gen III and $\mathrm{III}+$ ). As the current LWR plants contribute $70 \%$ of carbon-free electricity in the U.S., economic and safe operation of these plants in the coming decades are critical for the United States' stretched goals in energy security and climate change. The DOE "LWR Sustainability" Program, launched in FY-09 and expected to grow significantly in FY-10 and subsequent years, has focused on developing the LWR science and technology that enable life extension of the LWR plants beyond their current (renewed) license period (i.e., beyond 60 years). Aging of the plant equipment poses serious challenges on the plant reliability, safety margins, and eventually economic performance. In this context, development of advanced nuclear fuels for LWR, as well as understanding of fuel behavior (both prior to safety challenge and during safety transients), provides a pathway through which the plants may improve both safety and economy. For example, advanced fuel geometry (i.e., annular fuel) has been proposed as an innovative solution to increase the safety margin in LWRs. Advanced cladding materials, such as SiC, has also been proposed and investigated; as such, claddings offer potential for higher thermal tolerance under core dryout and uncovery conditions, as well as higher chemical resilience under different regimes of coolant chemistry. The former may lead to improved safety margin, while the later can provide flexibility in coolant chemistry that could be utilized to effectively tackle the effect of aging.

However, both the development of the advanced fuels (ceramic cladding, annular fuel, etc.) and the enhanced predictive capability of fuel behavior require substantial experimental and testing support. In particular, the new fuel cladding material and the new fuel geometry present significant uncertainties in using the existing methods on predicting fuel performance under a broad range of abnormal conditions, from reactivity initiated transients, to loss of coolant accidents, to severe sequences with fuel damage and melting. These methods developed for "classical" LWR fuels contain empirical models calibrated on data from experiments with different geometries and materials. Getting beyond this barrier is where the restarted program in TREAT reactor can prove timely and essential to the LWR Sustainability Program (LWR-SP).

It is suggested that a joint TREAT-LWR-SP feasibility study be conducted as soon as possible to bring together the two programs, to establish the requirements of TREAT modernization, which creates the capabilities that meet a set of high-priority items in the LWR Sustainability Program. This should take into account the planning in LWR-SP, including selection of advanced fuel types and cladding that will be supported by and investigated in LWR-SP. On the other hand, new capability provided by the modernized TREAT will influence the choice in LWR-SP since the TREAT may be more effective for addressing certain set of issues, thus selectively accelerating testing and qualification of certain fuel technologies.

\subsection{Input from High-Temperature Gas Reactor (Dave Petti)}

Transient reactivity testing has been identified by the NRC as a need for their confirmatory research associated with licensing a VHTR. ${ }^{\text {iii,iv }}$ Testing has been performed in the past for various fuel particles ${ }^{\mathrm{v}}$ (with slightly different dimensions than the current VHTR particle being qualified in the U.S.). The test conditions were not based on credible conditions that could occur in a reactor, but were conducted to identify particle failure thresholds (e.g., long-term adiabatic testing with externally driven particle power). More recently colleagues in Japan have performed reactivity testing of their coated particle fuel in their 
pulsed reactor (NSRR) and have systematically looked at the effect of the magnitude of the energy deposition on failure fraction. This work is part of the collaborative Gen-IV VHTR Fuel and Fuel Cycle activities.

Key limitations with the existing database are associated with the nature of the reactivity pulse that is used in the testing. Reactivity pulses are typical of those expected in LWRs in terms of the width of the pulse and the magnitude of the insertion; thus, the results are clearly conservative, but may in fact imply less margin than actually exists in gas reactor TRISO-coated particle fuels given the much longer prompt neutron lifetime and migration length in graphite and the lower levels of excess reactivity in gas reactor systems. Beyond these considerations, gas reactor vendors do not believe such testing is required because severe reactivity events are precluded by the design. (The reactor sits inside a thick bioshield and unmitigated rod ejections cannot occur since the movement of the control rod drives and housings will be limited by the bioshield.)

In terms of future testing, any reactivity testing needs to be able to simulate the actual timing and magnitude of a power pulse expected in fuel of a VHTR. ${ }^{\mathrm{vi}}$ An important issue is the simulation of heat transfer from the fuel test article in the longer, lower power pulses likely to be representative of a VHTR, which is not a consideration in the more typical LWR millisecond super-prompt critical pulses. Reactivity testing needs to be conducted in a manner where key parameters are varied systematically and in a controlled manner so that the critical fuel behavior can be understood and the margin to failure defined. If such a facility existed and could handle both unirradiated and irradiated fuel, the VHTR community would be interested in such a capability.

Given the long thermal time constant in VHTR loss of cooling transients, in-pile testing is not required to understand important safety-related fuel behavior phenomena as in other reactor systems. ${ }^{a}$ Thus, the most important safety testing for VHTR TRISO-coated particle fuel consists of postirradiation heating tests where fuel is subjected to high temperatures $\left(1400-1800^{\circ} \mathrm{C}\right)$ for long periods of time (100-200 hours) in a furnace in a hot cell in different environments (helium, air, and moisture depending on the specific accident sequence under consideration). These are currently planned in the VHTR fuel program.

\subsection{Input from JAEA (Tomoyasu Mizuno)}

The Japan Atomic Energy Agency provided an overview of the current research and development program in Japan including transient testing conducted in NSRR for the Japan LWR industry and the transient testing being conducted in the EAGLE program conducted in the IGR reactor in Kazakhstan. The purpose of this section is to identify the needs for full-length fuel pin transient testing, the experimental variants that require testing in transient conditions, and the desire to utilize the TREAT reactor to accomplish the research and development goals of the JAEA advanced reactor programs.

Figure 16 provides a graphical representation of the basic fuel behavior phenomena associated with and examined by transient testing of full-length fuel rods. Key phenomena can only be elucidated by full-length fuel testing. To support the development of a microstructural modeling and simulation capability, specific full-length fuel testing will be required.

a. For example, LWR in-pile LOCA tests included Semi-Scale and LOFT testing at INL and TREAT testing for LMFBR fuel pins. Integral safety demonstration tests have been carried out in both passive gas cooled and fast reactor systems (e.g., AVR, HTR-10, EBR-II), but their purpose was an integral safety demonstration and not a detailed study of fuel behavior under such conditions. 


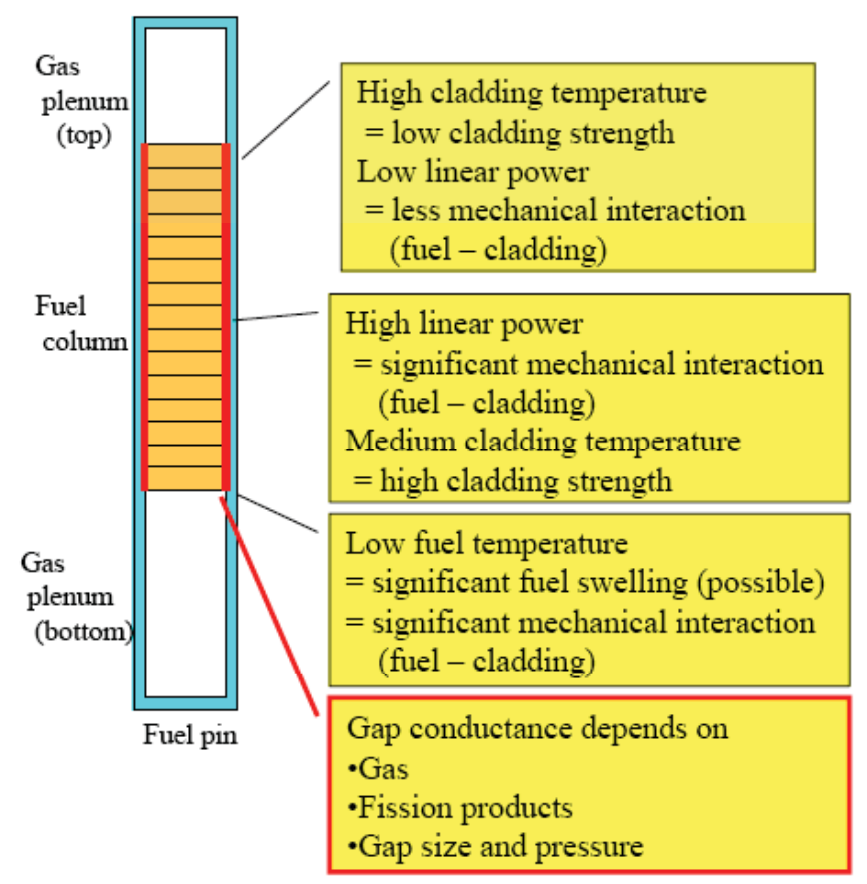

Figure 16. Full-length fuel testing phenomenology.

The fuel pin is an integrated system and must be tested as such. The following issues typically dominate fuel pin behavior in transient conditions:

- Internal gas pressure

- Fission products in fuel-clad gap

- Molten fuel motion

- Relationship between axial power profile and cladding temperature profile

- Local phenomena inside the fuel depend on the status and parameters of other parts of a fuel pin

- Full-length fuel pin tests with variants will provide important information that will lead to the scientific understanding of phenomena and their mechanisms in the real fuel pin system

- Variants: Fuel density, form, burnup, LHR, cladding material, transient condition.

A large quantity of steady state irradiated fuel is available today to support full length transient testing. The following fuels are of specific interest to the JAEA advance reactor fuel development program:

- $\quad$ EBR-II ORT* fuels

* DOE/PNC Operational Reliability Testing (Early ODS clad fuel pin, annular pellet fuel, etc.)

- $\quad$ FFTF CDE fuels

- Fuel pins irradiated in Joyo (50 cm fuel column, $160 \mathrm{~cm}$ fuel pin)

- GACID fuel pins in Monju (93 cm fuel column, $270 \mathrm{~cm}$ fuel pin).

JAEA requires results from transient testing of full-length fuel pins in the 2015 timeframe, with testing of fuels continuing through 2025 . 


\subsection{Input from AFCI Fuel Cycle Research and Development (Steve Hayes)}

The Advanced Fuel Cycle Initiative (AFCI) Transmutation Fuel Campaign is currently working to develop and qualify advanced reactor fuels appropriate for a challenging actinide transmutation mission. This work involves fabrication and subsequent steady-state irradiation testing ${ }^{\mathrm{b}}$ of candidate fuel forms that include significant quantities of plutonium and the minor actinides; postirradiation examination of these irradiated fuel experiments provides the information needed to establish the steady-state performance of these new fuels as well as generating data necessary to validate current fuel modeling efforts. However, fuel qualification also requires that the off-normal and transient performance of new fuels be understood. While some of this understanding can be obtained by furnace testing of irradiated fuels in a hot cell, as was always a part of fuel safety testing in past programs, other important data can only be obtained by the testing of previously irradiated fuels in a transient test reactor. This position paper addresses the needed transient performance data that can only be obtained in a transient test reactor.

\subsubsection{AFCI Transient Testing Requirements}

It is the intent of the AFCI program to make more extensive use of modeling and simulation (M\&S) in the present transmutation fuel qualification process as compared to past qualification programs. The ultimate objective of this would be a less-expensive and shortened time to transmutation fuel qualification, especially if the traditional irradiation-testing element of the qualification program can be reduced in scope. However, it is not yet clear at what point in the qualification process the M\&S activity will be capable of making contributions of this magnitude, nor what the position of the regulator will be to a departure from the traditional approach, which relies on demonstrated performance through prototypic, integral experiments conducted in transient test reactors. Thus, to be conservative, the AFCI transient testing requirements are given assuming the more traditional, experimental approach will be necessary.

AFCI transient testing needs can be categorized in three phases, which are generally undertaken sequentially: developmental testing, limit assessment, and confirmatory/ qualification testing. The objectives and test requirements for each phase is described in the following sections.

\subsubsection{Developmental Testing}

Developmental testing is undertaken to determine the inherent transient response of new fuel forms and identify potential concerns for reactor operations. The results obtained are of most use to fuel developers in informing fuel design. Test conditions typically proceed from mild to aggressive energy depositions and ramp rates. Since understanding intrinsic fuel response is the objective, some of these transient tests can be conducted using simple, capsule-type (i.e., miniature fuel rodlets) experiments in a transient test reactor, perhaps even without a prototypic cooling environment.

\subsubsection{Limit Assessment}

Limit assessment testing is undertaken to determine fuel pin failure thresholds and immediate postfailure consequences, and to establish limiting conditions of operation from the safety-related fuel performance perspective. The results obtained are of use to fuel developers, reactor designers, and safety analysts as fuel transient response will need to inform the reactor design activity. Transient tests in this category need to be performed on full-size fuel pins (and even mini-bundles of fuel pins) under prototypic coolant flow and fuel/cladding temperature conditions, with transient test conditions up to and beyond

b. Steady-state irradiation testing is currently underway in the ATR (INL) and Phénix (CEA-Cadarache). Future testing may include experiments in HFIR (ORNL), JOYO (Japan), China, and/or BOR-60 (Russia). 
fuel failure. Transient tests of this nature necessitate the ability to understand and quantify fuel movement during testing.

\subsubsection{Confirmatory/Qualification Testing}

Confirmatory/qualification transient testing is undertaken to confirm established thresholds and limiting conditions of operation for an established fuel and reactor design; as such, it is the final phase in the fuel qualification process. The results obtained are used in the preparation of the fuel/core Safety Case that will be the subject of regulatory review. Transient tests in this category need to be performed on full-size fuel pins and/or small bundles of pins under prototypic conditions of energy deposition, coolant flow, and fuel/cladding temperature profiles. 


\section{CONCLUSIONS}

The strengths of TREAT for transient fuel testing are clear:

- Capability to test prototypic, full-size fast reactor fuel pins, or even mini-bundles of up to seven fuel pins, made possible by the 48.0-in.-tall TREAT core.

- Capability to test fuel pins in flowing sodium loops of existing, proven design in order to provide prototypic cooling, resulting in prototypic fuel and cladding temperature profiles.

- Capability to provide prototypic fast reactor power transient shapes to either individual or small bundles of full-size fuel pins as test articles.

- Capability to observe fuel movement inside sodium loop containment during transient testing by means of the Fast Neutron Hodoscope (with resolution to $1.0 \mathrm{~mm}$ vertical, $0.2 \mathrm{~mm}$ horizontal).

- Use of existing infrastructure at INL's Materials and Fuels Complex (formerly Argonne-West) to load and unload sodium loops with the irradiated fuel pins that would be part of any TREAT experiment, as well as the capability to perform postirradiation examinations of the fuels after the transient test in the Hot Fuel Examination Facility (HFEF) located on the same DOE site as TREAT.

Transient fuel testing needs can only be fully met by utilizing TREAT. The fuel development and research task will require transient performance data generated on full-length fuel designs.

This conclusion is implicitly validated by the ongoing interactions and direct requests from the JAEA, who are similarly engaged in a fast reactor fuel development activity. The JAEA fuel development and qualification team is actively pursuing talks with the U.S. related to a TREAT restart, as they recognize it as a necessary element in the fuel research and development process as established in Japan.

Transient testing of fuels and materials is important for development of advanced computer modeling and simulation that describes fuel behavior under off-normal conditions. TREAT is an ideal facility for this testing because of its flexibility, proven operation, and material condition. The opportunity exists to develop advanced instrumentation and data collection, which can support modeling and simulation needs much better than was possible in the past. In order to take advantage of these opportunities, test programs must be carefully designed to yield basic information to support modeling before conducting integral performance tests.

An early start of TREAT and operation at low power (in the 2015 timeframe) would provide significant dividends in training, development of instrumentation, and checkout of reactor systems. The importance of TREAT to the future of advance nuclear power research and development is characterized by the following:

- TREAT is an absolute necessity in the suite of reactor fuel test capabilities

- TREAT yields valuable information on reactivity effects, margins to failure, fuel dispersal, and failure propagation

- Most importantly, interpretation of TREAT experiment results is a stringent test of the integrated understanding of fuel performance. 


\section{REFERENCES}

i. T. H. Bauer, A. E. Wright, W. R. Robinson, J. W. Holland, and E. A. Rhodes, "Behavior of Modern Metallic Fuel in TREAT Transient Overpower Tests," Nuclear Technology, Vol. 92, pp. 325-352, December 1990.

ii. R. Herbert, M. H. Wood, C. W. Hunter, J. M. Kramer, and A. E. Wright, "Fuel Pin Failure in the PFR/TREAT Experiments," published in Vol. 1 of "Science and Technology of Fast Reactor Safety" (proceedings of an international conference held in Guernsey, England, May 12-16, 1986, sponsored by the British Nuclear Energy Society).

iii. USNRC, “Advanced Reactor Research Program (Draft),” March 2007 (ADAMS \#ML070740576).

iv. USNRC Presentations, “Advanced Reactor Research Plan,” (ADAMS \#ML091030059), “Advanced Reactor Research Plan for Fuels Analysis," (ADAMS \#ML091030081), April 2009.

v. IAEA, TECDOC-978, "Fuel and Fission Product Behavior in Gas Cooled Reactors," Nov. 1997.

vi. NUREG, CR-6944, Next Generation Nuclear Plant Phenomena Identification and Ranking Tables (PIRTs) (NUREG/CR-6944) - Volume 6: Process Heat and Hydrogen Co-Generation PIRTs. 2007. 